\title{
Geochemical evaluation of low salinity hot water injection to enhance heavy oil recovery from carbonate reservoirs
}

\author{
Ji Ho Lee ${ }^{1} \cdot$ Kun Sang Lee ${ }^{1}$
}

Received: 3 February 2018/Published online: 19 November 2018

(C) The Author(s) 2018

\begin{abstract}
Although low salinity water injection (LSWI) has recovered residual oil after the conventional waterflood, highly viscous oil has remained in heavy oil reservoirs. Hot water injection is an economic and practical method to improve oil mobility for viscous oil reservoirs. It potentially controls temperature-dependent geochemical reactions underlying the LSWI mechanism and oil viscosity. Therefore, this study has modeled and evaluated a hybrid process of low salinity hot water injection (hot LSWI) to quantify synergistic effects in heavy oil reservoirs. In comparison to seawater injection (SWI) and LSWI, hot LSWI results in more cation ion-exchange $\left(\mathrm{Ca}^{2+}\right.$ and $\left.\mathrm{Mg}^{2+}\right)$ and more wettability modification. Hot LSWI also reduces oil viscosity. In core-scaled systems, it increases oil recovery by $21 \%$ and $6 \%$ over SWI and LSWI. In a pilotscaled reservoir, it produces additional oil by $6 \%$ and $3 \%$ over SWI and LSWI. Probabilistic forecasting with uncertainty assessment further evaluates the feasibility of hot LSWI to consider uncertainty in the pilot-scaled reservoir and observes enhanced heavy oil production. This study confirms the viability of hot LSWI due to synergistic effects including enhanced wettability modification and oil viscosity reduction effects.
\end{abstract}

Keywords Low salinity water injection - Hot water injection - Wettability modification - Geochemical reaction . Viscosity reduction

\section{Introduction}

Conventional waterflood has been widely deployed to maintain pressure of reservoirs and pressurize depleted reservoirs. While it typically recovers $35 \%$ of original oil in place (OOIP) from conventional reservoirs, heterogeneity, unfavorable mobility, and wettability limitations serve to retain the remaining oil in the reservoir (Lake et al. 2014). Enhanced oil recovery (EOR) methods have been developed to overcome unfavorable conditions. Low salinity water injection (LSWI), which is based on tuning the ionic composition of brine, has emerged as a substitute for expensive EOR. Many experiments have observed that wettability modification is a primary contribution to the LSWI effect (Austad et al. 2005; Zhang et al. 2006, 2007; Lager et al.

Edited by Yan-Hua Sun

Kun Sang Lee

kunslee@hanyang.ac.kr

1 Department of Earth Resources and Environmental Engineering, Hanyang University, Seoul 04763, South Korea
2008; Yousef et al. 2011). The studies have observed carboxylic acid in crude oil is the main factor for oil-wetness of chalk. They have found an influence of complex geochemical reactions on the carboxylic acid modifying wetness of chalk. The EOR research group at University of Stavanger (Austad et al. 2005; Zhang et al. 2006, 2007) has carried out chromatographic wettability tests, spontaneous imbibition tests, and coreflood experiments. They used various oil-wet chalk cores, evaluated with the chromatographic wettability test. A chromatographic wettability test tracked the non-adsorbing tracer and injected ions and determined a wettability index of the chalk cores. They injected various compositions of brines into the oil-wet chalk cores and evaluated oil recovery. Using the observations, they have proposed a mechanism that adsorption of $\mathrm{SO}_{4}{ }^{2-}$ and co-adsorption of $\mathrm{Ca}^{2+}$ and $\mathrm{Mg}^{2+}$ are responsible for wettability modification of chalk cores. The study also concluded that the mechanism is sensitive to temperature and a high temperature (above $70{ }^{\circ} \mathrm{C}$ ) is a favorable condition to observe the mechanism. Yousef et al. (2011) conducted various experiments of IFT (interfacial tension), NMR (nuclear magnetic resonance) measurement, and coreflood. The study observed an IFT 
reduction when low salinity water is injected. From the NMR measurement, change of pore distribution was observed and attributed to mineral dissolution. Based on the experiments, the study concluded there is a wettability modification effect to enhance oil recovery and proposed that an alteration of surfaces of carbonate rock alters reservoir wettability. Further work of Ayirala et al. (2018) constructed a coreflooding system with zeta potential measurement and measured zeta potential when different diluted brines were injected into cores. They also simulated the experiments at different temperatures $\left(25,60^{\circ} \mathrm{C}\right)$ to reveal the relationship between temperature and zeta potential. Hiorth et al. (2010) proposed another mechanism with rock dissolution, rather than rock surface charge, is responsible for the wettability modification effect. Yutkin et al. (2018) examined the proposed mechanisms of LSWI by calculating surface charge potential using experimental results. Their findings of rapid dissolution of carbonate rock, $\mathrm{pH}$ buffering by rock dissolution, diffuse double layer collapse, and instantaneous equilibrium between aqueous species and mineral dissolution are at variance with the proposed mechanisms except for MIE (multicomponent ionic exchange) theory (Lager et al. 2008) and ligand-ion-exchange oil release. While the exact mechanism is still unclear, it is obvious that LSWI contributes to wettability modification and geochemical reactions are responsible for the LSWI effect.

A few studies have constructed a numerical LSWI model by implementing its mechanism (Qiao et al. 2015; Awolayo et al. 2017). Qiao et al. (2015) proposed a mechanism modeling approach using the surface complexation model and the electrical diffuse layer calculation in carbonate core systems. The surface complexation model describes surface reactions that adhere aqueous ions and carboxylic groups to the surface of calcite in aqueous, oleic, and solid phases. An additional extensive experimental database of carbonate reservoirs is required for the approach. The experimental difficulties associated with the acquisition and interpretation of electro-kinetic measurements and surface titration data as well as complex surface chemistry of carbonate minerals are barriers to the approach (Wolthers et al. 2008). In addition, this approach is not practical in pilot-scaled modeling because of the various unclear parameters. Another numerical study by Awolayo et al. (2017) developed a LSWI model coupled with aqueous reactions, mineral reactions, ion-exchange reactions of $\mathrm{Ca}^{2+}$ and $\mathrm{Mg}^{2+}$, and adsorption reaction of $\mathrm{SO}_{4}{ }^{2-}$. It modeled the underlying mechanism of LSWI using the concept of MIE (multicomponent ionic exchange) theory (Lager et al. 2008). Therefore, this study adapted the approach of Awolayo et al. (2017) to formulate LSWI mechanism.

Gachuz-Muro and Sohrabi (2013, 2014) investigated this promising LSWI for heavy oil recovery. Normally, crude oil is classified as light (higher than $31.1^{\circ} \mathrm{API}$ ), medium (from $31.1^{\circ}$ API to $22.3^{\circ} \mathrm{API}$ ), heavy (less than $22.3^{\circ} \mathrm{API}$ ), and extra heavy (less than $10^{\circ} \mathrm{API}$ ). The experiments used heavy oil $\left(14.12^{\circ} \mathrm{API}, 53,484 \mathrm{cP}\right.$ at $20{ }^{\circ} \mathrm{C}$ ). The heavy crude oil production has several technical issues of wettability, highly viscous oil, asphaltene precipitation, etc. (Gachuz-Muro and Sohrabi 2014; Guo et al. 2016). Gachuz-Muro and Sohrabi (2013, 2014) described the properties of oil and brines used in the coreflooding experiments. Ionic composition of $\mathrm{SW}$ is equivalent to the brine composition from the Gulf of Mexico. Compositions of formation water (FW), seawater (SW), and low salinity water (LSW) are indicated in Table 1 . The heavy crude oil viscosity decreases as temperature increases from 20 to $115^{\circ} \mathrm{C}$, as shown in Fig. 1 .

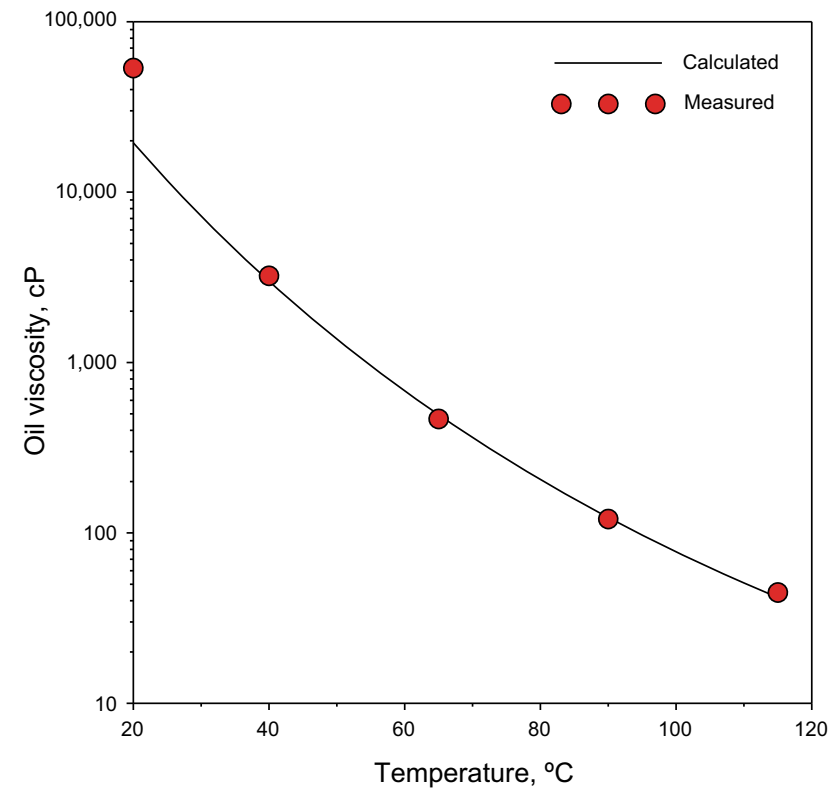

Fig. 1 Temperature-dependent oil viscosity

Table 1 Properties and compositions of brines

\begin{tabular}{|c|c|c|c|c|c|c|c|c|c|c|c|}
\hline \multirow[t]{2}{*}{ Brine } & \multicolumn{9}{|c|}{ Composition, mg/L } & \multirow[t]{2}{*}{$\mathrm{pH}$} & \multirow[t]{2}{*}{ Ionic strength, molality } \\
\hline & $\mathrm{Na}^{+}$ & $\mathrm{Ca}^{2+}$ & $\mathrm{Mg}^{2+}$ & $\mathrm{K}^{+}$ & $\mathrm{Ba}^{2+}$ & $\mathrm{Sr}^{2+}$ & $\mathrm{Cl}^{-}$ & $\mathrm{SO}_{4}{ }^{2-}$ & $\mathrm{HCO}_{3}^{-}$ & & \\
\hline FW & 9614.97 & 320.36 & 218.94 & - & - & - & $15,117.25$ & 550.63 & 1135.90 & 8.01 & 0.46 \\
\hline SW & $11,429.38$ & 429.60 & 1361.60 & 351.10 & 0.01 & 8.37 & $20,040.00$ & 3500.00 & 47.58 & 7.80 & 0.66 \\
\hline LSW & 1142.93 & 42.96 & 136.16 & 35.11 & - & 0.83 & 2004.00 & 350.00 & 4.75 & 7.20 & 0.07 \\
\hline
\end{tabular}


Gachuz-Muro and Sohrabi (2014) conducted LSWI experiments with limestone cores. In the coreflooding experiment, SW and LSW (10 times-diluted SW) were injected at a relatively high temperature $\left(92{ }^{\circ} \mathrm{C}\right)$. They reported that SW injection (SWI) of 15 pore volume (PV) obtained an oil recovery up to $36.8 \%$ and successive LSW injection (LSWI) of $15 \mathrm{PV}$ after SWI produced additional oil recovery of $15.3 \%$. The enhanced oil recovery proved the potential LSWI effect and wettability modification in heavy oil reservoirs.

A study (Lapham 2012) reported that the global oil reserves are estimated to contain 35\% light oil, $29 \%$ medium oil, $26 \%$ heavy oil, and $10 \%$ extra heavy oil. Though the heavy oil reserve is potentially huge in the world, especially South America, the heavy oil recovery factor still remains low (Meyer et al. 2003). In addition, heavy oil in fractured carbonate reservoirs represents $25 \%$ $30 \%$ of the total oil in place in the Middle East (Saidi 1988). The thermal EOR has a potential to enhance the heavy oil recovery. The Wafra oil field in Oman already shows the huge potential for thermal EOR in at least a portion of the field. Lapham evaluated the extensive EOR projects and concluded that hybrid thermal EOR combining with other EOR is efficient to recover the heavy oil. Therefore, thermal EOR with LSWI can be a promising hybrid EOR for heavy oil reservoirs. When this hybrid EOR technology is developed and secures practical feasibility, it will expand the heavy oil market. One of the great candidate thermal EORs for the hybrid EOR is hot water injection. It is a waterflood-based EOR similar to LSWI. The field tests and experiments already have confirmed that hot water injection reduces heavy oil viscosity and improves heavy oil production (Kovscek et al. 2000; Alajmi et al. 2009; Duval et al. 2015). Additionally, it potentially influences pore connectivity because of temperaturedependent mineral reactions (Kovscek et al. 2000). The geochemical reactions are known to be sensitive to both temperature and pressure (Appelo and Postma 2005), so hot water injection significantly affects geochemical reactions.

This study proposes the hybrid EOR technology combining hot water injection and LSWI, hereafter referred to as low salinity hot water injection (hot LSWI) for heavy oil recovery. Previously, Abass and Fahmi (2013) conducted hot LSWI experiments using intermediate heavy oil (1700 $\mathrm{cP}$ at $65^{\circ} \mathrm{C}$ ) and sandstone cores from the BAW oil field in Sudan. Its results proved the enhanced heavy oil production and synergistic effects of the hybrid hot LSWI, however, the study lacked investigations of temperature-dependent geochemical reactions and carbonate rock during hot LSWI. Therefore, this study simulates hybrid hot LSWI considering temperature-dependent geochemical reactions and evaluates the heavy oil recovery of hot LSWI from carbonate reservoirs. The heavy oil production and synergistic effects of hot LSWI are compared to those of SWI and LSWI in core- and pilot-scaled systems.

\section{Basic theories}

Transportation modeling of multi-phases and -components is coupled with multiple modeling of geochemical reactions and Henry's law. The geochemical reactions involve aqueous reactions, mineral dissolution/precipitation, and ion exchange and they are sensitive to temperature. In geochemical reactions, ion activity, equilibrium constant, selectivity coefficient, and reaction rate are all a function of temperature and are determined by various experiments (Wolery and Daverler 1992; Appelo and Postma 2005). Viscosity and density of brine depend on temperature and ion activity as well.

\subsection{Aqueous reactions}

Ionic concentration in the aqueous phase is determined when the reaction quotient or ion activity product (IAP) reaches the temperature-dependent equilibrium constant at a specific temperature. The temperature-dependent equilibrium constant is obtained from Kharaka et al. (1988) and Delany and Lundeen (1991).

$Q_{\alpha}-K_{\mathrm{eq}, \alpha}=0$

$Q_{\alpha}=\prod_{k=1}^{n_{\mathrm{aq}}} a_{k}^{v_{k, \alpha}}$

$\log K_{\mathrm{eq}, \alpha}=A_{1}+A_{2} T+A_{3} T^{2}+A_{4} T^{3}$

where $\alpha$ is the aqueous reaction, $K_{\mathrm{eq}, \alpha}$ is the temperaturedependent equilibrium constant at a specific temperature, $Q_{\alpha}$ is the IAP, $k$ is the component, $n_{\mathrm{aq}}$ is the number of aqueous reactions, $a_{k}$ is the ionic activity, $v_{k, \alpha}$ is the stoichiometry coefficients of an aqueous reaction, $A_{1}, A_{2}, A_{3}$, and $A_{4}$ are the fitting parameters to determine the equilibrium constant at a specific temperature, and $T$ denotes temperature.

In geochemical reactions, effective ionic concentration is considered rather than molality, because of electrostatic interactions among ions in the aqueous phase. The effective ionic concentration is represented by ion activity, which is determined by the activity coefficient and molality. The activity coefficient is a function of temperature and ionic strength. Davies, Debye-Hückel, and modified DebyeHückel (B-dot) models can calculate activity coefficient. The modified Debye-Hückel (B-dot) model determines reasonable activity coefficient of ions when ionic strength varies up to 1 molality (Bethke 2007). In addition, various 
geochemical software EQ3/EQ6, CHILLER, SOLMINEQ, and SPECE8 and REACT use the model. Therefore, this study uses the modified Debye-Hückel model to calculate temperature-dependent activity coefficient of ions. In this study, Bethke (2007) is used to calculate them.

$a_{k}=\gamma_{k} m_{k}$

$\log \gamma_{k}=-\frac{A_{\gamma} z_{k}^{2} \sqrt{I}}{1+\dot{a}_{k} B_{\gamma} \sqrt{I}}+\dot{B} I$

$I=\frac{1}{2} \sum_{k=1}^{n_{\mathrm{aq}}} m_{k} z_{k}^{2}$

where $\gamma_{k}$ defines the activity coefficient, $m_{k}$ is the molality, $A_{\gamma}$ and $B_{\gamma}$ are temperature-dependent coefficients, and $\dot{B}$ is the temperature-dependent coefficients $\left(\mathrm{m}^{-1}\right), I$ is the ionic strength, $\dot{a}_{k}$ is the ion-size parameter (m), and $z_{k}$ is the charge number of ions.

\subsection{Mineral dissolution/precipitation}

In this study, calcite $\left(\mathrm{CaCO}_{3}\right)$ and dolomite $\left(\mathrm{CaMg}\left(\mathrm{CO}_{3}\right)_{2}\right)$ are assumed to be the main minerals. The dissolution or precipitation of minerals is characterized by heterogeneous, non-equilibrium, and slow reactions. The mineral dissolution or precipitation is a kinetic reaction and the rate of the mineral reaction is affected by mineral type, ionic composition, temperature, and, $\mathrm{pH}$ (Bethke 2007; Morse and Arvidson 2002; Soulaine et al. 2017). This study simulates the rate-dependent kinetic reaction following the rate law (Bethke 2007) and the rate law does not take account of the effect of pH directly. Kharaka et al. (1988) and Delany and Lundeen (1991) simulated the mineral reactions of calcite and dolomite.

$\mathrm{CaCO}_{3}+\mathrm{H}^{+} \leftrightarrow \mathrm{Ca}^{2+}+\mathrm{HCO}_{3}^{-}$

$\mathrm{CaMg}\left(\mathrm{CO}_{3}\right)_{2}+2 \mathrm{H}^{+} \leftrightarrow \mathrm{Ca}^{2+}+2 \mathrm{HCO}_{3}^{-}+\mathrm{Mg}^{2+}$

$r_{\beta}=\hat{A}_{\beta} k_{\beta}\left(1-\frac{Q_{\beta}}{K_{\text {eq }, \beta}}\right)$

$Q_{\beta}=\prod_{k=1}^{n_{\mathrm{aq}}} a_{k}^{v_{k, \beta}}$

where $\beta$ indicates mineral type, calcite or dolomite, $r_{\beta}$ is the reaction rate $\left(\mathrm{mol} \mathrm{m}^{-3} \mathrm{~s}^{-1}\right), k_{\beta}$ is the reaction rate constant, $\hat{A}_{\beta}$ is the reactive surface area of a mineral $\left(\mathrm{m}^{-1}\right)$, $K_{\text {eq. } \beta}$ is the solubility product constant at a specific temperature, $Q_{\beta}$ is the IAP, and $v_{k, \beta}$ is the stoichiometric coefficients of a mineral reaction.

Dissolution/precipitation of minerals provides/consumes aqueous ionic species in brine. The rate of

Table 2 Properties of limestone core in the experiment (Gachuz-Muro and Sohrabi 2014) and simulation

\begin{tabular}{lllll}
\hline Pore volume, $\mathrm{m}^{3}$ & Porosity & Permeability, $\mathrm{mD}$ & Water saturation & Temperature, ${ }^{\circ} \mathrm{C}$ \\
\hline 15.55 & 0.2064 & 19.4 & 0.32 & 92 \\
\hline
\end{tabular}

Table 3 Geochemical reactions

\begin{tabular}{ll}
\hline Phase & Reaction \\
\hline Aqueous reactions & $\mathrm{H}^{+}+\mathrm{OH}^{-} \leftrightarrow \mathrm{H}_{2} \mathrm{O}$ \\
& $\mathrm{CO}_{2}(\mathrm{aq})+\mathrm{H}_{2} \mathrm{O} \leftrightarrow \mathrm{H}^{+}+\mathrm{HCO}_{3}{ }^{-}$ \\
& $\mathrm{CaHCO}_{3}{ }^{+} \leftrightarrow \mathrm{Ca}^{2+}+\mathrm{HCO}_{3}{ }^{-}$ \\
& $\mathrm{MgHCO}_{3}{ }^{+} \leftrightarrow \mathrm{HCO}_{3}{ }^{-}+\mathrm{Mg}^{2+}$ \\
& $\mathrm{NaHCO}_{3} \leftrightarrow \mathrm{HCO}_{3}{ }^{-}+\mathrm{Na}^{+}$ \\
& $\mathrm{CaCO}_{3}\left(\mathrm{H}^{+}\right) \leftrightarrow \mathrm{Ca}^{2+}+\mathrm{HCO}_{3}{ }^{-}$ \\
& $\left(\mathrm{H}^{+}\right)\left(\mathrm{MgCO}_{3}\right) \leftrightarrow \mathrm{HCO}_{3}{ }^{-}+\mathrm{Mg}^{2+}$ \\
& $\left(\mathrm{H}^{+}\right)\left(\mathrm{NaCO}_{3}{ }^{-}\right) \leftrightarrow \mathrm{HCO}_{3}{ }^{-}+\mathrm{Na}^{+}$ \\
& $\left(\mathrm{H}^{+}\right)\left(\mathrm{MgOH}^{+}\right) \leftrightarrow \mathrm{H}_{2} \mathrm{O}+\mathrm{Mg}^{2+}$ \\
& $\left(\mathrm{H}^{+}\right)\left(\mathrm{NaOH}^{+} \leftrightarrow \mathrm{H}_{2} \mathrm{O}+\mathrm{Na}^{+}\right.$ \\
& $\mathrm{CaSO}_{4} \leftrightarrow \mathrm{Ca}^{2+}+\mathrm{SO}_{4}{ }^{2-}$ \\
& $\mathrm{Na}_{2} \mathrm{SO}_{4} \leftrightarrow 2\left(\mathrm{Na}^{+}\right)+\mathrm{SO}_{4}{ }^{2-}$ \\
& $\mathrm{MgSO}_{4} \leftrightarrow \mathrm{Mg}^{2+}+\mathrm{SO}_{4}{ }^{2-}$ \\
& $\mathrm{CaCO}_{3}+\mathrm{H}^{+} \leftrightarrow \mathrm{Ca}^{2+}+\mathrm{HCO}_{3}{ }^{-}$ \\
& $\mathrm{CaMg}\left(\mathrm{CO}_{3}\right)_{2}+2 \mathrm{H}^{+} \leftrightarrow \mathrm{Ca}^{2+}+2 \mathrm{HCO}_{3}{ }^{-}+\mathrm{Mg}^{2+}$ \\
& $\mathrm{Na}^{+}+0.5 \mathrm{Ca}_{2} \leftrightarrow \mathrm{Na}^{+} \mathrm{X}+0.5 \mathrm{Ca}^{2+}$ \\
& $\mathrm{Na}^{+}+0.5 \mathrm{Mg}_{2} \mathrm{X}_{2} \leftrightarrow \mathrm{Na}^{-} \mathrm{X}_{+}+0.5 \mathrm{Mg}^{2+}$ \\
Mineral dissolution/precipitation & $\mathrm{H}^{+}+\mathrm{Na}^{+} \mathrm{X} \leftrightarrow \mathrm{H}_{-}-\mathrm{X}+\mathrm{Na}^{+}$ \\
\hline & \\
\hline
\end{tabular}




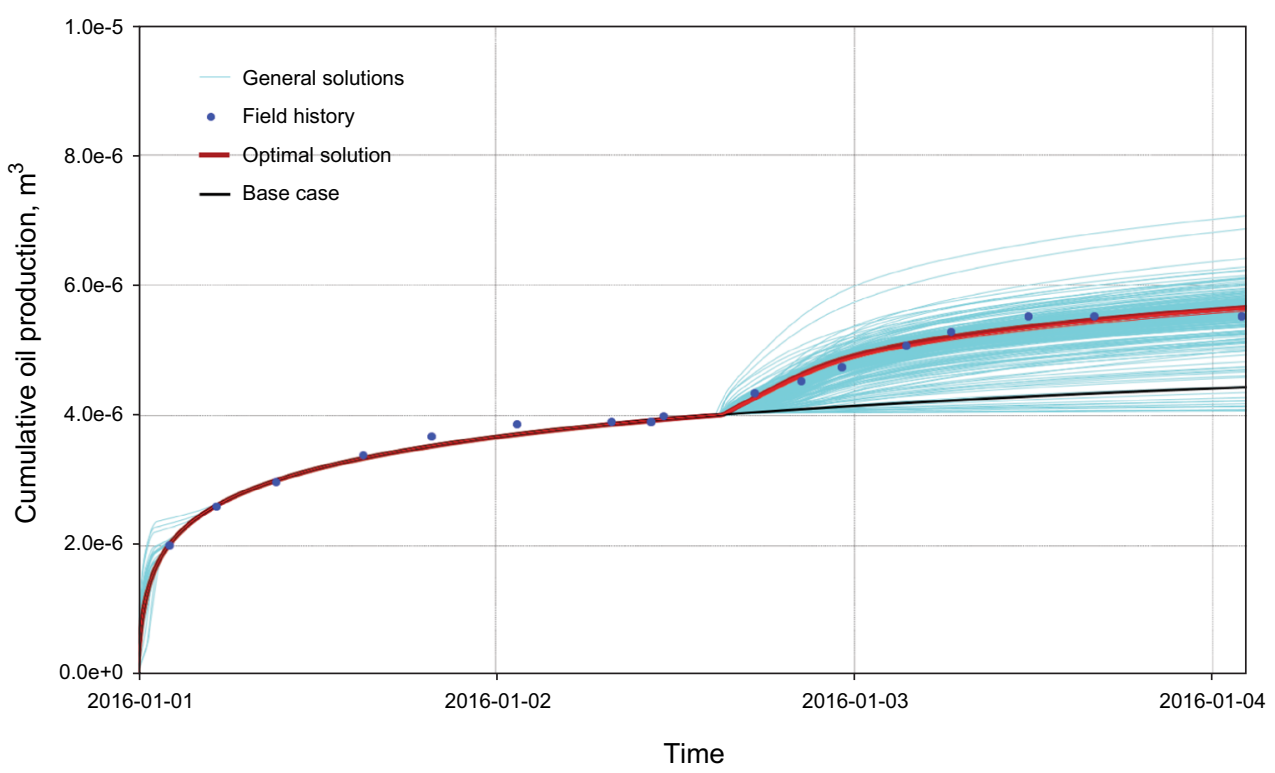

Fig. 2 History matching result for successive SWI-LSWI in terms of oil production $\left(\mathrm{m}^{3}\right)$

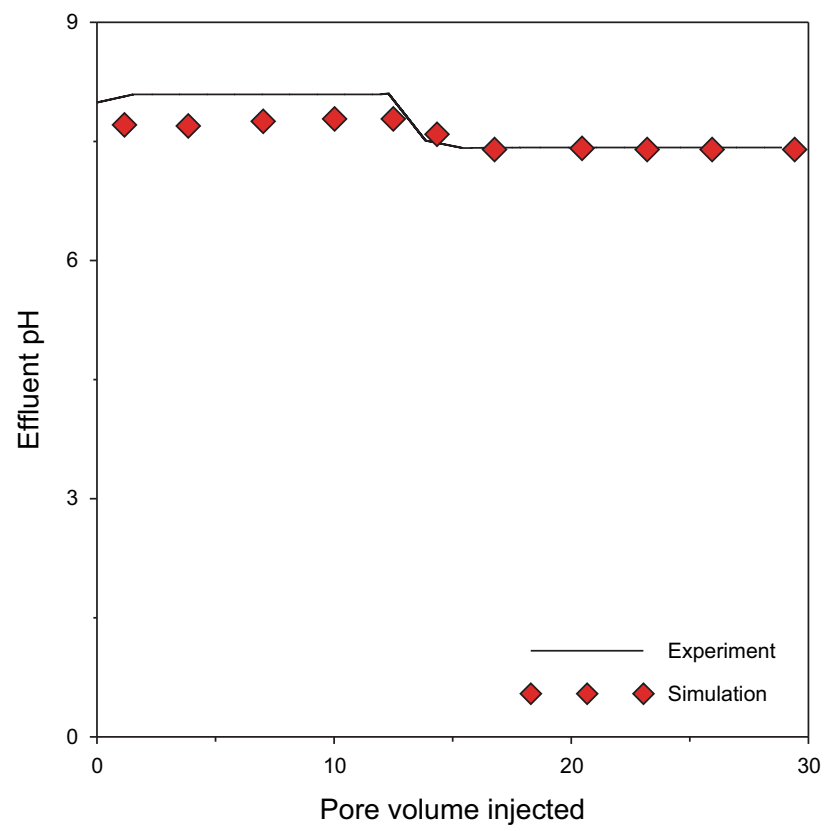

Fig. 3 Comparison of effluent $\mathrm{pH}$ between experiment and simulation

generation/consumption is closely related to the rate of mineral change. Reaction rate and stoichiometric coefficients of mineral dissolution/precipitation determine the rate of mineral generation/consumption in brine.

$\gamma_{k, \beta}=v_{k, \beta} r_{\beta}$

where $\gamma_{k, \beta}$ indicates the reaction rate (consumption/production) of ionic aqueous components $\left(\mathrm{mol} \mathrm{m}^{-3} \mathrm{~s}^{-1}\right)$.

Temperature influences the solubility product constant, activity, and kinetic reaction rate in mineral reactions. The

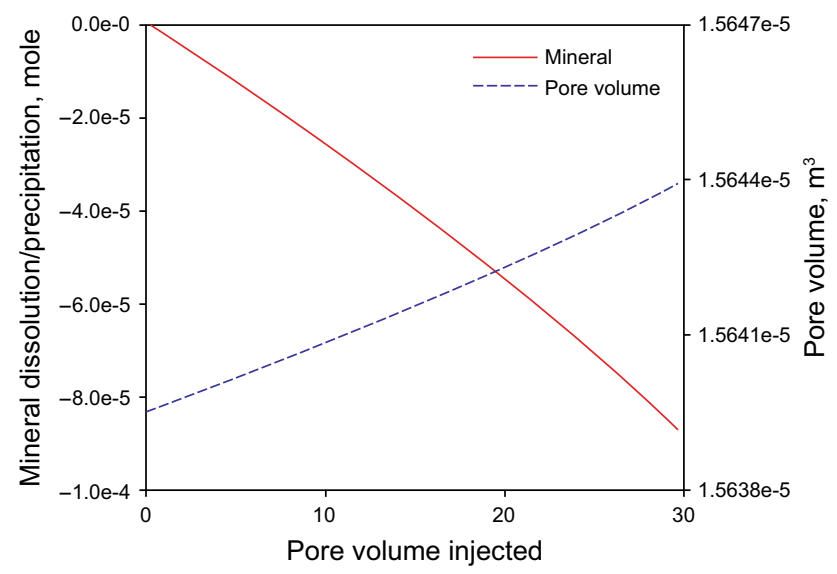

Fig. 4 History of mineral dissolution/precipitation (mole) and pore volume $\left(\mathrm{m}^{3}\right)$ for successive SWI-LSWI

solubility product constant is determined by the empirical polynomial formulation.

$\log K_{\mathrm{eq}, \beta}=B_{0}+B_{1} T_{1}+B_{2} T^{2}+B_{3} T^{3}+B_{4} T^{4}$

where $B_{0}, B_{1}, B_{2}, B_{3}$, and $B_{4}$ represent fitting parameters. The temperature-dependent activity coefficient has been explained in Eqs. (4)-(6). Lastly, the kinetic reaction rate is adjusted at an elevated temperature in terms of the Arrhenius equation.

$k_{\beta}=k_{\mathrm{o} \beta} \exp \left[-\frac{E_{a \beta}}{R}\left(\frac{1}{T}-\frac{1}{T_{\mathrm{o}}}\right)\right]$

where $k_{\mathrm{o} \beta}$ indicates reaction rate constant at the reference temperature $\left(\mathrm{mol} \mathrm{m}^{-2} \mathrm{~s}^{-1}\right), E_{a \beta}$ is the activation energy 
$(8.314 \mathrm{~J} /(\mathrm{mol} \mathrm{K})), R$ is the universal gas constant, and $T_{\mathrm{o}}$ is the reference temperature $(\mathrm{K})$.

\subsection{Ion-exchange}

Following the approach of Awolayo et al. (2017), this study models wettability modification due to ion-exchange reactions. The ion-exchangeable cations $\left(\mathrm{H}^{+}, \mathrm{Na}^{+}, \mathrm{Ca}^{2+}\right.$, and $\mathrm{Mg}^{2+}$ ) interact with the rock surface. This ion-exchange is a reversible reaction. The state of adsorbed cations and ion-exchanged cation is determined when the IAP becomes the selectivity coefficient. The activities of the exchangeable species follow the Gaines-Thomas convention. The number of ion-exchanged ions is generally expressed with an equivalent fraction. The amount of positive charge that adheres to a mineral surface is defined with cation exchange capacity (CEC).

$$
\begin{aligned}
& \mathrm{H}^{+}+\mathrm{Na}-\mathrm{X} \leftrightarrow(\mathrm{H}-\mathrm{X})+\mathrm{Na}^{+} \\
& \mathrm{Na}^{+}+\frac{1}{2}\left(\mathrm{Ca}-\mathrm{X}_{2}\right) \leftrightarrow(\mathrm{Na}-\mathrm{X})+\frac{1}{2} \mathrm{Ca}^{2+} \\
& \mathrm{Na}^{+}+\frac{1}{2}\left(\mathrm{Mg}-\mathrm{X}_{2}\right) \leftrightarrow(\mathrm{Na}-\mathrm{X})+\frac{1}{2} \mathrm{Mg}^{2+} \\
& K_{\mathrm{H} / \mathrm{Na}}=\frac{\left[\alpha\left(\mathrm{Na}^{+}\right)\right] \alpha(\mathrm{H}-\mathrm{X})}{\alpha\left(\mathrm{H}^{+}\right)[\alpha(\mathrm{Na}-\mathrm{X})]} \\
& K_{\mathrm{Na} / \mathrm{Ca}}=\frac{\left[\alpha\left(\mathrm{Ca}^{2+}\right)\right]^{0.5} \alpha(\mathrm{Na}-\mathrm{X})}{\alpha\left(\mathrm{Na}^{+}\right)\left[\alpha\left(\mathrm{Ca}-\mathrm{X}_{2}\right)\right]^{0.5}} \\
& K_{\mathrm{Na} / \mathrm{Mg}}=\frac{\left[\alpha\left(\mathrm{Mg}^{2+}\right)\right]^{0.5} \alpha(\mathrm{Na}-\mathrm{X})}{\alpha\left(\mathrm{Na}^{+}\right)\left[\alpha\left(\mathrm{Mg}-\mathrm{X}_{2}\right)\right]^{0.5}}
\end{aligned}
$$

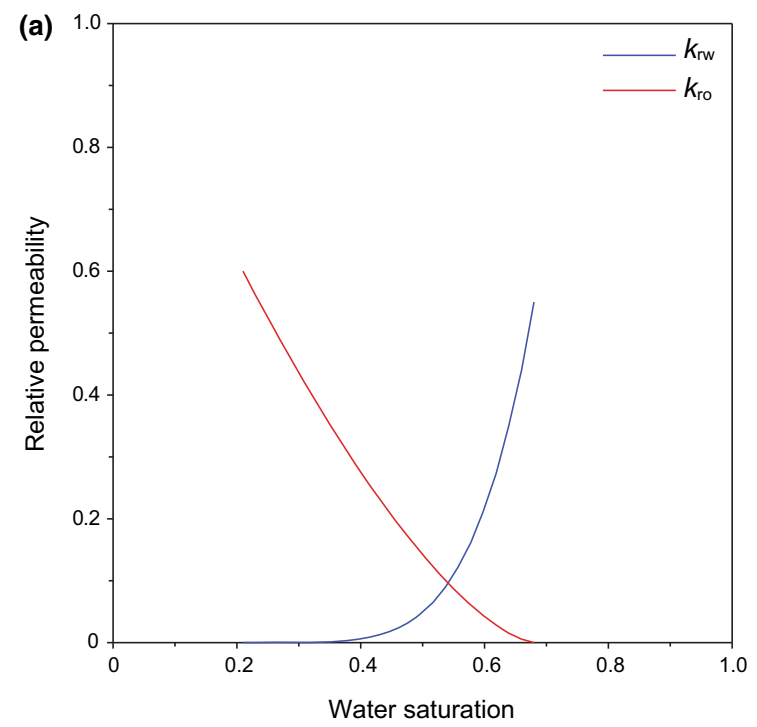

$\beta_{\mathrm{H}-\mathrm{X}}=\frac{N_{\mathrm{H}-\mathrm{X}}}{N_{\mathrm{Na}-\mathrm{X}}+2 N_{\mathrm{Ca}-\mathrm{X}_{2}}+2 N_{\mathrm{Mg}-\mathrm{X}_{2}}+N_{\mathrm{H}-\mathrm{X}}}$

$\beta_{\mathrm{Na}-\mathrm{X}}=\frac{N_{\mathrm{Na}-\mathrm{X}}}{N_{\mathrm{Na}-\mathrm{X}}+2 N_{\mathrm{Ca}-\mathrm{X}_{2}}+2 N_{\mathrm{Mg}-\mathrm{X}_{2}}+N_{\mathrm{H}-\mathrm{X}}}$

$\beta_{\mathrm{Ca}-\mathrm{X}_{2}}=\frac{N_{\mathrm{Ca}-\mathrm{X}_{2}}}{N_{\mathrm{Na}-\mathrm{X}}+2 N_{\mathrm{Ca}-\mathrm{X}_{2}}+2 N_{\mathrm{Mg}-\mathrm{X}_{2}}+N_{\mathrm{H}-\mathrm{X}}}$

$\beta_{\mathrm{Mg}-\mathrm{X}_{2}}=\frac{N_{\mathrm{Mg}-\mathrm{X}_{2}}}{N_{\mathrm{Na}-\mathrm{X}}+2 N_{\mathrm{Ca}-\mathrm{X}_{2}}+2 N_{\mathrm{Mg}-\mathrm{X}_{2}}+N_{\mathrm{H}-\mathrm{X}}}$

$C E C=\frac{N_{\mathrm{Na}-\mathrm{X}}+2 N_{\mathrm{Ca}-\mathrm{X}_{2}}+2 N_{\mathrm{Mg}-\mathrm{X}_{2}}}{\varphi}$

where $\mathrm{X}$ indicates the surface of carbonate rock, $K_{\mathrm{H} / \mathrm{Na}}$, $K_{\mathrm{Na} / \mathrm{Ca}}$, and $K_{\mathrm{Na} / \mathrm{Mg}}$ are the selectivity coefficients, $\beta_{\mathrm{H}-\mathrm{X}}$, $\beta_{\mathrm{Na}-\mathrm{X}}, \beta_{\mathrm{Ca}-\mathrm{X}_{2}}$ and $\beta_{\mathrm{Mg}-\mathrm{X}_{2}}$ are the equivalent fractions,

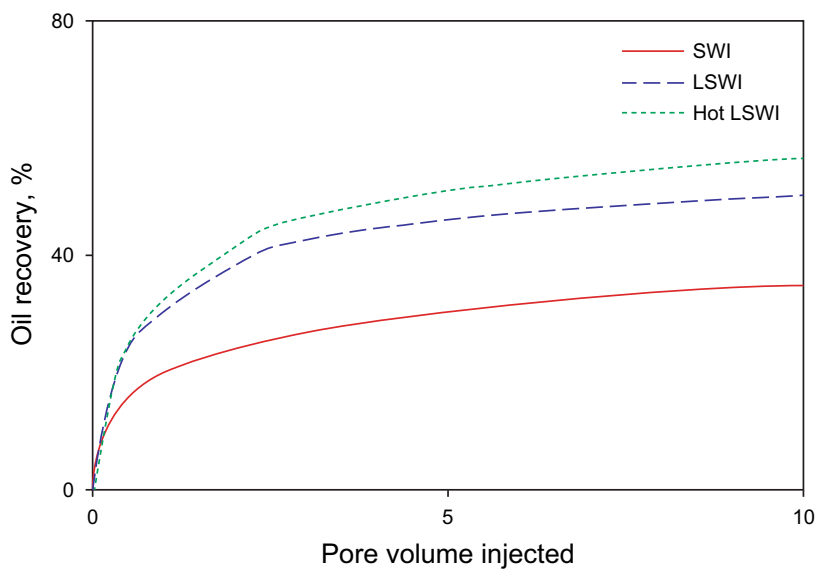

Fig. 6 History of oil recovery (\%) for SWI, LSWI, and hot LSWI

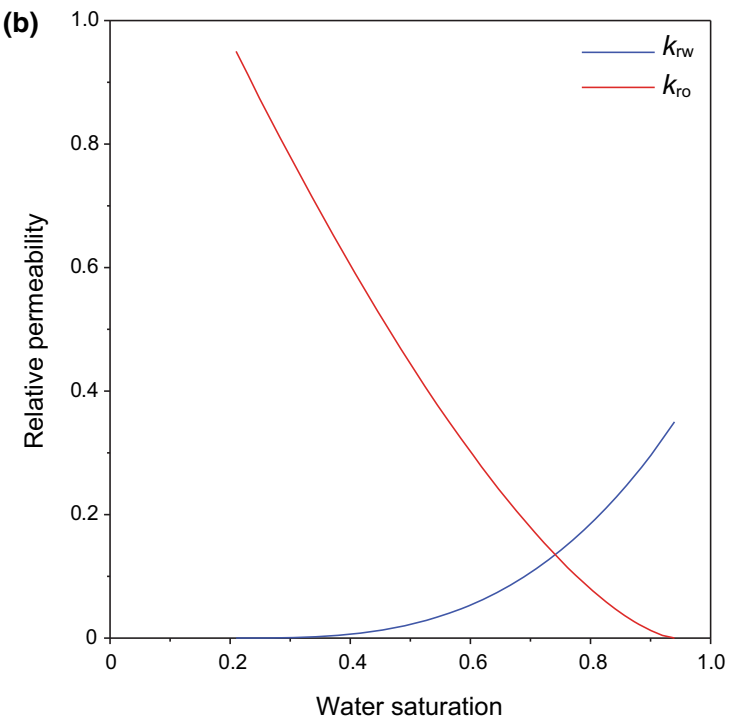

Fig. 5 Relative permeability curves before (a) and after (b) wettability modification 
$N_{\mathrm{H}-\mathrm{X}}, N_{\mathrm{Na}-\mathrm{X}}, N_{\mathrm{Ca}-\mathrm{X}_{2}}$, and $N_{\mathrm{Mg}-\mathrm{X}_{2}}$ are the number of moles of ion-exchanged $\mathrm{H}^{+}, \mathrm{Na}^{+}, \mathrm{Ca}^{2+}$, and $\mathrm{Mg}^{2+}, C E C$ is the cation exchange capacity (meq/kg rock).

In the thermodynamic system, the van't Hoff equation introduces a temperature effect on the selectivity coefficient of ion-exchange reactions (SenGupta 2017). The temperature-dependent selectivity coefficient is calculated with a standard enthalpy change and reference selectivity coefficient. The data of standard enthalpy change and
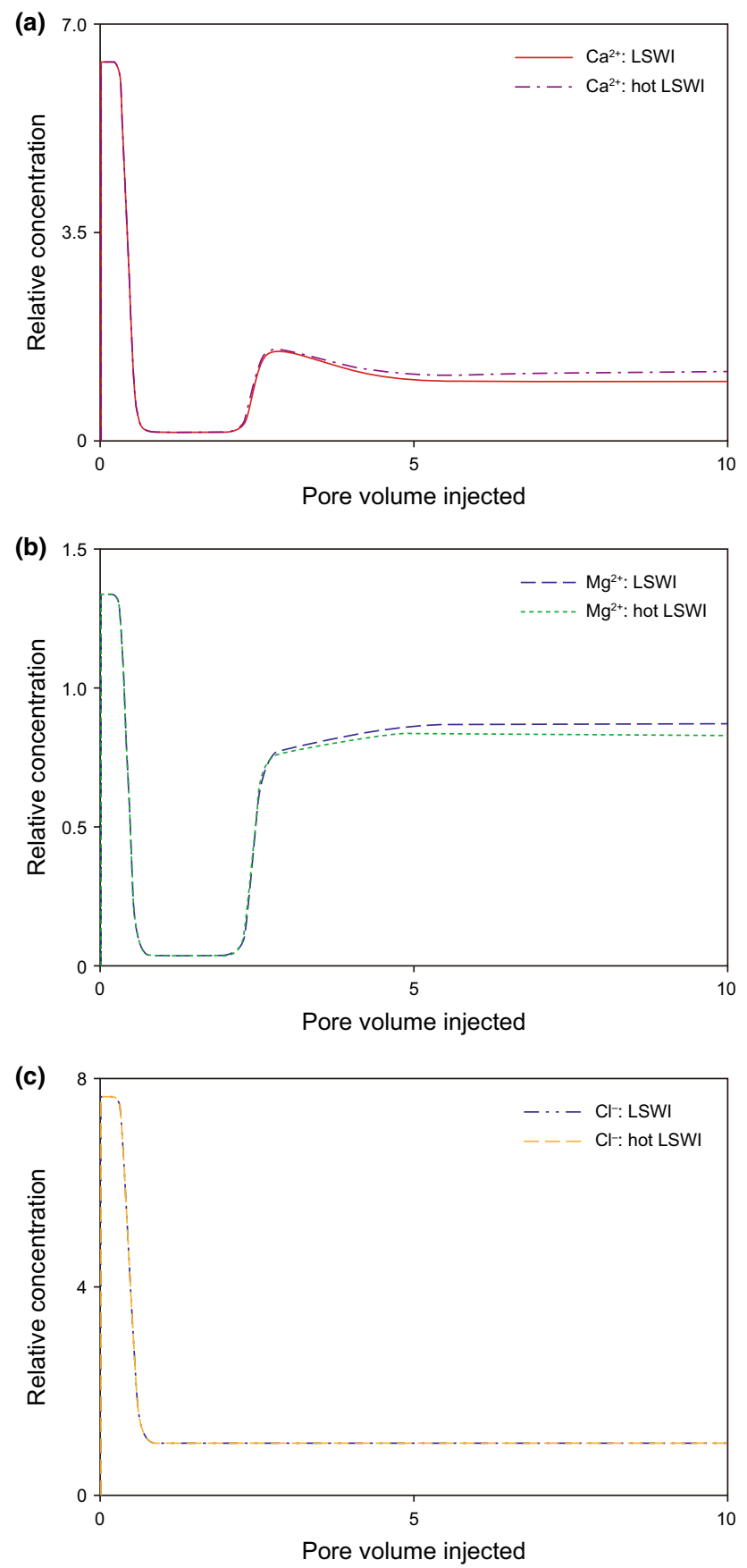

Fig. 7 History of relative concentrations of $\mathrm{Ca}^{2+}, \mathrm{Mg}^{2+}$, and $\mathrm{Cl}^{-}$for LSWI, and hot LSWI reference selectivity coefficient is provided from the PHREEQC ( $\mathrm{pH}$ Redox Equilibrium) software database (Appelo and Postma 2005).

$$
\begin{aligned}
& \log K_{\mathrm{Na} / \mathrm{Ca}, T_{1}}=\log K_{\mathrm{Na} / \mathrm{Ca}, T_{2}}-\frac{\Delta H_{\mathrm{r}}^{\mathrm{o}}}{2.303 R}\left(\frac{1}{T_{1}}-\frac{1}{T_{2}}\right) \\
& \log K_{\mathrm{Na} / \mathrm{Mg}, T_{1}}=\log K_{\mathrm{Na} / \mathrm{Mg}, T_{2}}-\frac{\Delta H_{\mathrm{r}}^{\mathrm{o}}}{2.303 R}\left(\frac{1}{T_{1}}-\frac{1}{T_{2}}\right)
\end{aligned}
$$

where $K_{\mathrm{Na} / \mathrm{Ca}, T}$ and $K_{\mathrm{Na} / \mathrm{Mg}, T}$ indicate the selectivity coefficients at a specific temperature, and $\Delta H_{\mathrm{r}}^{\mathrm{o}}$ is the reaction enthalpy of the system $\left(\mathrm{kJ} \mathrm{mol}^{-1}\right)$.

\section{Numerical simulation}

Numerical modeling of hot LSWI is developed using a series of LSWI experiments (Gachuz-Muro and Sohrabi 2013, 2014) targeting heavy oil reservoirs. Using these experiments, LSWI coreflooding coupled with geochemical modeling is simulated with GEM developed from CMG. The software is a fully-coupled geochemical and compositional simulator (Nghiem et al. 2004). It is a multiphase and multicomponent flow simulator with phase and chemical equilibrium and rate-dependent mineral dissolution/precipitation. Using the adaptive implicit method, a few grid blocks are solved fully implicitly and the other blocks are solved explicitly according to the blocks' implicitness. In terms of the stability criterion, CourantFriedrichs-Lewy (CFL) is used to determine the degree of implicitness and the criterion can be used for switching both from explicit to implicit and from implicit to explicit discretizations of a block. In addition, this simulator offers Newton's method to solve the nonlinear systems of reservoir simulation. This study selects the recommended convergence criteria for Newton's method and the tolerances of the criteria follow: pressure change with $3.55 \mathrm{kPa}$; temperature change with $0.001{ }^{\circ} \mathrm{C}$; relative change of hydrocarbon component molar density with 0.01 ; and relative change of water component molar density with 0.01 . In terms of the phase and geochemical equilibrium calculations, the tolerance of the criterion is the sum of square residual with $1 \times 10^{-10}$.

The 1-D numerical core model representing a carbonate core is composed of 20 grid blocks. The properties of the core model are summarized in Table 2. The brine compositions of FW, SW, and LSW (10 times-diluted SW) to be modelled are indicated in Table 1. The ionic strengths of the brines are calculated using PHREEQC software and also described in Table 1 . The temperature-dependent oil viscosity (Gachuz-Muro and Sohrabi 2013) is modeled with modified Pedersen's equation (Pedersen and Fredenslund 1987) and depicted in Fig. 1. When temperatures 
are above $40{ }^{\circ} \mathrm{C}$, the viscosity of the modeled oil has error less than $6 \%$ compared to experiments. In this coreflooding model, SW injection (SWI) of $15 \mathrm{PV}$ and LSW injection (LSWI) of $15 \mathrm{PV}$ after SWI are simulated corresponding to the experimental design (Gachuz-Muro and Sohrabi 2014).

The LSWI effect modifies the wettability of reservoirs. The wettability is a complex characteristic of a reservoir and characterized with relative permeability and residual oil saturation. For the modeling of the LSWI effect, this study attributes wettability modification to ion-exchange of cations following the approach of Awolayo et al. (2017). During LSWI, increasing equivalent fractions of $\mathrm{Ca}^{2+}$ is assumed to modify wettability changing the relative permeability and residual oil saturation. The change of the relative permeability and residual oil saturation is quantified through a history-matching process. The history matching is carried out with CMOST software and uses the production data of successive SWI-LSWI coreflooding (Gachuz-Muro and Sohrabi 2014) to determine a modification of relative permeability and residual oil saturation. The history-matching process applies a DECE (Designed Exploration and Controlled Evolution) algorithm, an interactive process of designed exploration stage (experimental design and Tabu search) and controlled evolutionary stage.

In the modelling of coreflooding, a few assumptions are necessary due to the lack of experimental data (GachuzMuro and Sohrabi 2014): (1) The general displacement rate of waterflooding is assumed to be about $1 \mathrm{ft} /$ day. (2) Capillary pressure has been ignored because of the high injection pressure. (3) The cations $\left(\mathrm{K}^{+}, \mathrm{Ba}^{2+}\right.$, and $\left.\mathrm{Sr}^{2+}\right)$ at relatively low concentrations are neglected. Batch simulations using PHREEQC are carried out to validate the assumption. The $\mathrm{pH}$ values of the seawater and low salinity water are calculated when the seawater and low salinity water have and do not have the cations. The results of the batch simulations show that the difference of $\mathrm{pH}$ is only about 0.01 for both brines. With this assumption, the recalculated $\mathrm{pH}$ values of the brines using PHREEQC are used. (4) The geochemical reactions (aqueous reactions, mineral dissolution/precipitation, and ion-exchange) to be modelled are listed in Table 3 and the database of the geochemical reaction modeling is from Wolery and Daverler (1992) and Appelo and Postma (2005). (5) The density and viscosity of brine are a function of temperature, pressure, and $\mathrm{NaCl}$ concentration. They are calculated with Rowe and Chou (1970)'s and Kestin et al. (1981)'s models. (6) The chalk is assumed to contain $95 \%$ calcite and $5 \%$ dolomite. (7) Heavy oil behavior with asphaltene potentially influences on the performance of hot LSWI due to formation damage. However, the experiments (GachuzMuro and Sohrabi 2013, 2014) have a lack of experimental results for asphaltene, so this numerical simulation neglects asphaltene kinetics consideration and formation damage evaluation.

\section{Results and discussion}

Firstly, an unknown relative permeability and modification of relative permeability during successive secondary SWI and tertiary LSWI are quantified through a history-matching process. The history-matching draws multiple history-matched models based on experimental data (Fig. 2). In terms of a best history-matched model, modification of relative permeability due to wettability modification effect is evaluated. We next investigated the coreflooding of secondary SWI, LSWI, and hot LSWI $\left(115^{\circ} \mathrm{C}\right)$, respectively, in terms of oil viscosity, geochemical reactions, and wettability modification. Thermal energy during hot LSWI potentially contributes to additional heavy oil production. It is evaluated in core- and pilot-scaled systems, respectively. Because heat loss is crucial for thermal EOR, the simulation of the pilotscaled system considers heat loss to over-burden and underburden shale formations. Lastly, a probabilistic forecast methodology is employed to estimate oil recovery of LSWI and hot LSWI in a pilot-scaled heterogeneous reservoir. While the previous assessments of hot LSWI in the coreand pilot-scaled systems incorporate a best history-matched relative curve, probabilistic forecast analysis assesses multiple relative permeability curves obtained from the historymatching process to reflect inherent uncertainty. In Fig. 2, the multiple history-matched models are indicated with red lines. From the results of probabilistic forecasting using the multiple history-matched models, performance of hot LSWI is compared to that of LSWI considering uncertainty in a pilot-scaled reservoir.

\subsection{SWI-LSWI}

In the result of history matching process (Fig. 2), the blue dots and red solid line indicate experimental and historymatched oil production respectively. In an analysis of a best history-matched model, LSWI recovers additional $15 \%$ of OOIP after SWI (Fig. 2). The effluent $\mathrm{pH}$ values of simulation and experiment are compared to verify the geochemical reaction modeling (Fig. 3). Both simulation and experiment correspondingly show an effluent $\mathrm{pH}$ of 7.4 after LSWI. Both SWI and LSWI slightly dissolve calcite and dolomite minerals and increase the pore volume (Fig. 4). Considering total pore volume of the core, the pore volume change is negligible. In comparison to SWI, LSWI results in increased equivalent fractions of $\mathrm{Ca}^{2+}$ and $\mathrm{Mg}^{2+}$ by $183 \%$ and $115 \%$, respectively, and decreased equivalent fraction of $\mathrm{Na}^{+}$by $57 \%$. These results indicate that LSWI leads to more ion-exchange of $\mathrm{Ca}^{2+}$ and $\mathrm{Mg}^{2+}$ 

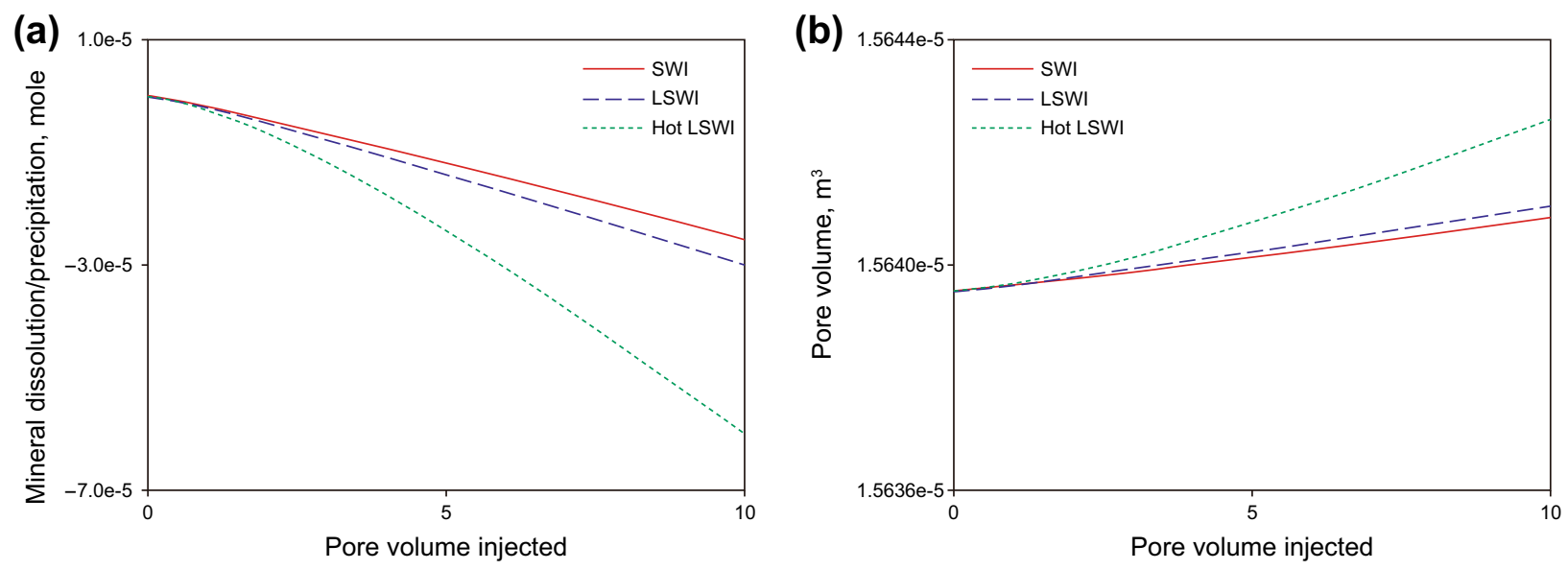

Fig. 8 History of mineral dissolution/precipitation (mole) and pore volume $\left(\mathrm{m}^{3}\right)$ for SWI, LSWI, and hot LSWI

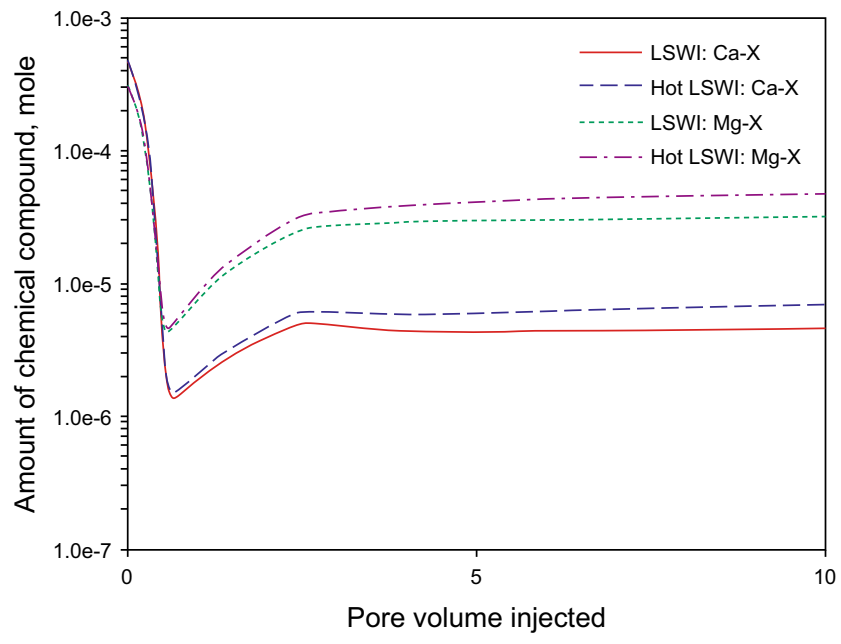

Fig. 9 History of the amount (mole) of chemical compounds of $\mathrm{Ca}-\mathrm{X}$ $\left(\mathrm{CaHCO}_{3}{ }^{+}, \mathrm{CaCO}_{3}, \mathrm{CaSO}_{4}\right)$ and $\mathrm{Mg}-\mathrm{X}\left(\mathrm{MgHCO}_{3}{ }^{+}, \mathrm{MgCO}_{3}\right.$, $\mathrm{MgOH}^{+}, \mathrm{MgSO}_{4}$ ) during LSWI and hot LSWI

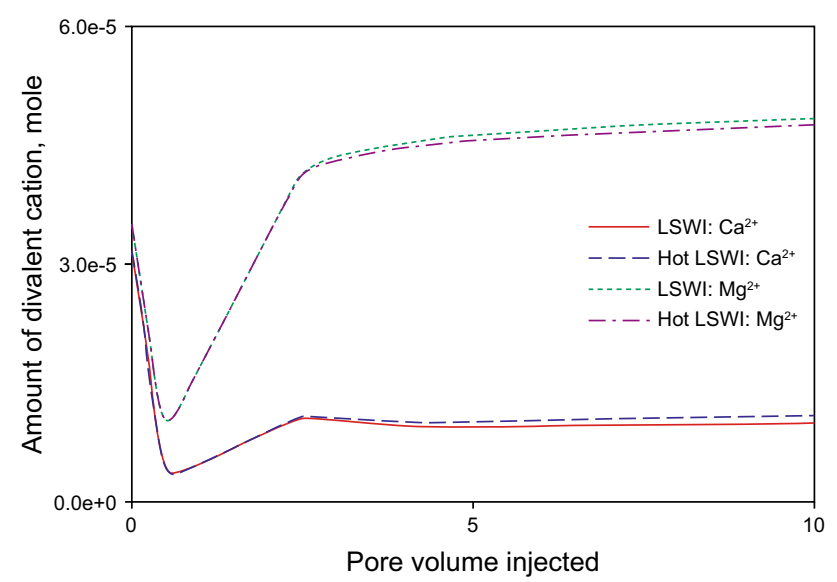

Fig. 10 History of the amount (mole) of $\mathrm{Ca}^{2+}$ and $\mathrm{Mg}^{2+}$ during LSWI and hot LSWI

rather than that of $\mathrm{Na}^{+}$. As described in Fig. 5, LSWI increasing ion-exchange of $\mathrm{Ca}^{2+}$ and $\mathrm{Mg}^{2}$ improves

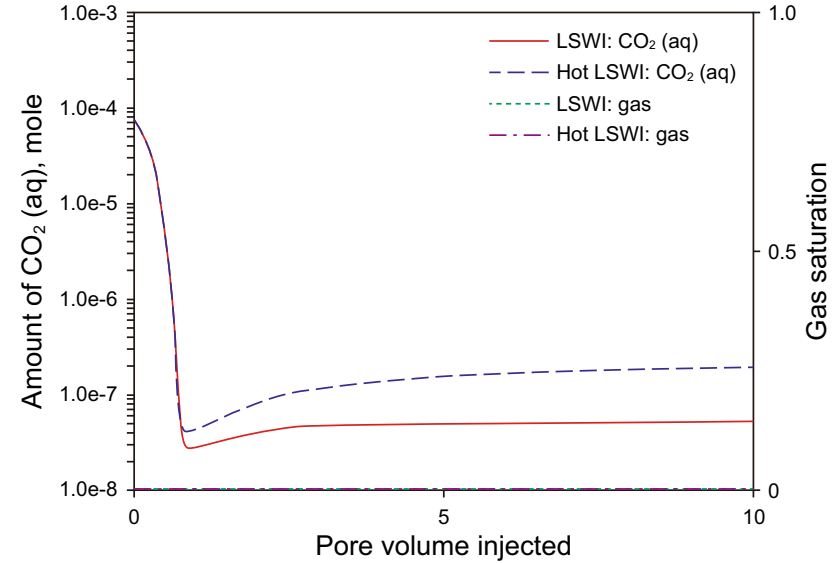

Fig. 11 History of the amount of $\mathrm{CO}_{2}(\mathrm{aq})$ (mole) and gas saturation during LSWI and hot LSWI

Table 4 Reservoir properties

\begin{tabular}{ll}
\hline Properties & Value \\
\hline Pore volume, $\mathrm{m}^{3}$ & $1.682 \times 10^{4}$ \\
Original oil in place, $\mathrm{m}^{3}$ & $1.142 \times 10^{4}$ \\
Average permeability, $\mathrm{mD}$ & 200 \\
Vertical to horizontal permeability ratio & 0.1 \\
Temperature, ${ }^{\circ} \mathrm{C}$ & 92 \\
Heat capacity, $\mathrm{J} /(\mathrm{kg} \mathrm{K})$ & \\
Carbonate reservoir & 969 \\
Shale & 1214 \\
Thermal conductivity, $\mathrm{J} /(\mathrm{m} \mathrm{s} \mathrm{K})$ & \\
Carbonate reservoir & 2.40 \\
Shale & 0.88 \\
\hline
\end{tabular}

wettability modifying relative permeability. LSWI reduces residual oil saturation by 0.12 units. It also increases the end point relative permeability of oil by $58 \%$ and decreases the end point relative permeability of water by $41 \%$, respectively. 


\subsection{Core-scaled system: hot LSWI}

Using the history-matched coreflooding model, secondary modes of SWI, LSWI, and hot LSWI are simulated for 10 PV and the results are compared. Figure 6 describes heavy oil productions for SWI, LSWI, and hot SWI, respectively.

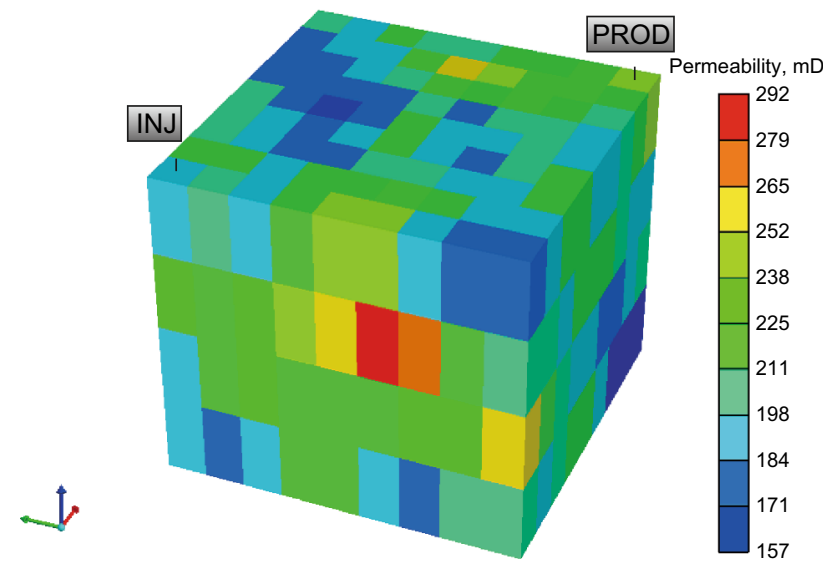

Fig. 12 Permeability $(\mathrm{mD})$ distribution of pilot-scaled reservoir

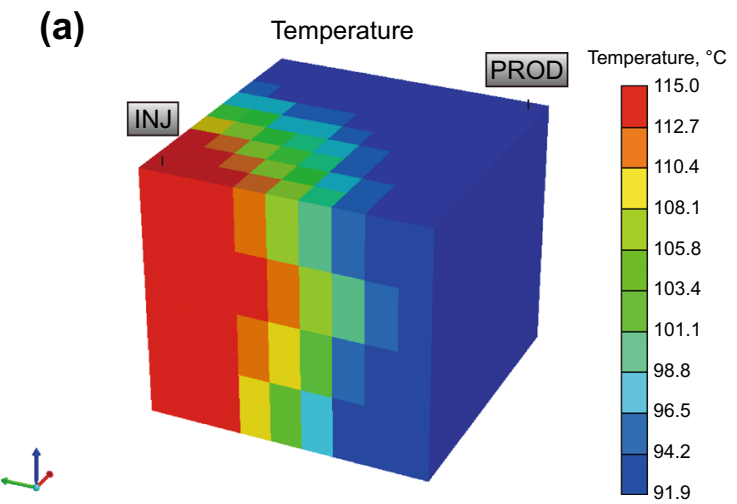

Secondary SWI recovers only $35 \%$ of OOIP after $10 \mathrm{PV}$ injection. LSWI and hot LSWI produce additional heavy oil with $15 \%$ and $21 \%$ over SWI.

In comparison with SWI, LSWI increases the equivalent fractions of $\mathrm{Ca}^{2+}$ and $\mathrm{Mg}^{2+}$ by $182 \%$ and $116 \%$, respectively. The change of effluent concentration of $\mathrm{Ca}^{2+}$ also confirms increasing the cation-exchange of $\mathrm{Ca}^{2+}$. Figure 7 depicts the concentration of ions $\left(\mathrm{Ca}^{2+}, \mathrm{Mg}^{2+}\right.$, and $\left.\mathrm{Cl}^{-}\right)$in effluent divided by their concentration in the injection fluid, i.e. the relative concentration of the ions. The $\mathrm{Cl}^{-}$ hardly participates in geochemical reactions, so the $\mathrm{Cl}^{-}$is assumed to be a tracer. After breakthrough with $1 \mathrm{PV}$ injection, delay of $\mathrm{Ca}^{2+}$, not $\mathrm{Cl}^{-}$, is observed and it is the result of cation-exchange of $\mathrm{Ca}^{2+}$. In addition, the relative concentration of $\mathrm{Ca}^{2+}$ becomes higher than 1 after a $2.5 \mathrm{PV}$ injection. This observation is attributed to substitution of $\mathrm{Ca}^{2+}$ by $\mathrm{Mg}^{2+}$ in terms of cation-exchange. The increasing equivalent fraction of $\mathrm{Ca}^{2+}$ is responsible for wettability modification effect following LSWI. As a result, LSWI produces as much as $15 \%$ more heavy oil than SWI due to wettability modification effects (Fig. 6). In terms of

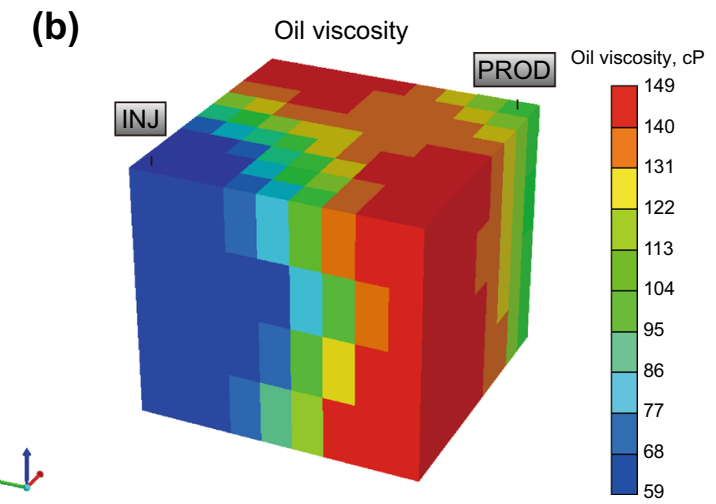

Fig. 13 Distribution of temperature $\left({ }^{\circ} \mathrm{C}\right)$ and oil viscosity $(\mathrm{cP})$ for hot LSWI

(a)

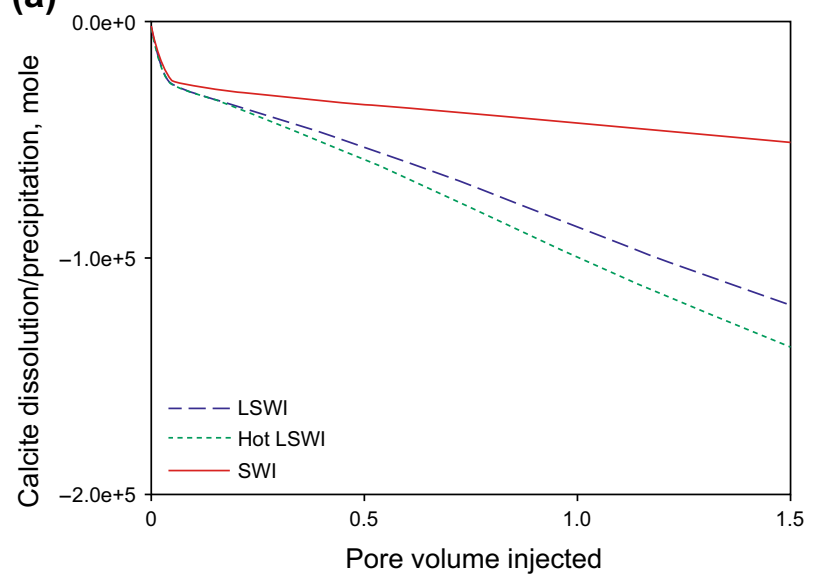

(b)

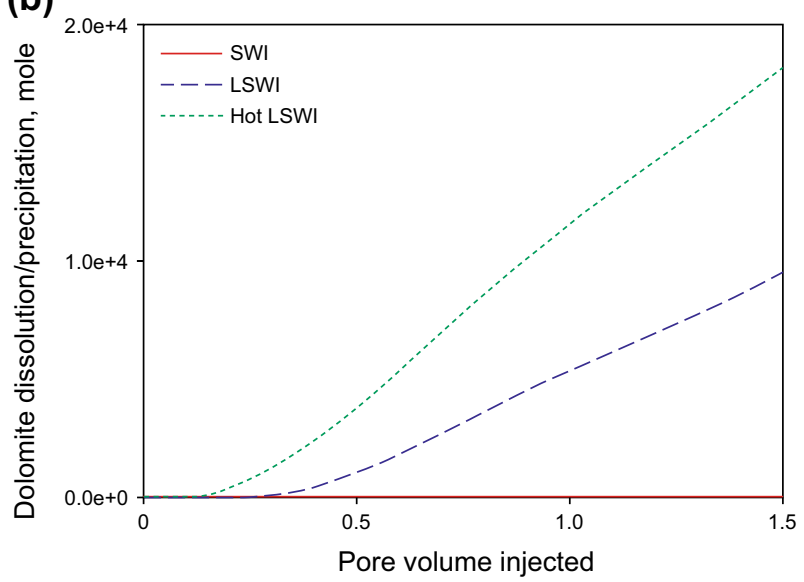

Fig. 14 Mineral dissolution/precipitation (mole) for LSWI and hot LSWI 
mineral reaction, LSWI dissolves more mineral by $16 \%$ over SWI (Fig. 8a). The mineral dissolution slightly increases porosity and pore volume (Fig. $8 b$ ).

When hybrid hot LSWI is simulated into the core-scaled system, hot water injection influences geochemical reactions and reduces oil viscosity. Hot LSWI accelerates mineral dissolution by $235 \%$ over SWI and increases pore volume (Fig. 8). The increased porosity by mineral dissolution increases permeability, but the increments of porosity and permeability in the core-scaled system are negligible. In addition, hot LSWI causes a significant cation ion-exchange. In comparison to SWI, hot LSWI increases average equivalent fractions of $\mathrm{Ca}^{2+}$ and $\mathrm{Mg}^{2+}$ by a factor of three and two, respectively. The relative concentration of $\mathrm{Ca}^{2+}$ is also investigated to confirm the cation-exchange (Fig. 7). There is a delay of $\mathrm{Ca}^{2+}$ at breakthrough due to cation-exchange and a higher relative concentration of $\mathrm{Ca}^{2+}$ than 1 at $2.5 \mathrm{PV}$ injection is observed due to cation-exchange of $\mathrm{Mg}^{2+}$. The increased equivalent fraction of $\mathrm{Ca}^{2+}$ results in wettability modification. Therefore, hot LSWI could preserve the wettability modification effect. The next compares hot LSWI and LSWI. While both hot LSWI and LSWI inject equivalent ionic composition of brine, almost double the amount of dolomite and calcite are dissolved and pore volume increases more in hot LSWI (Fig. 8). The dolomite dissolution generates both $\mathrm{Ca}^{2+}$ and $\mathrm{Mg}^{2+}$ and calcite dissolution produces only $\mathrm{Ca}^{2+}$. The hot LSWI produces more chemical compounds of $\mathrm{Ca}^{2+}$ and $\mathrm{Mg}^{2+}\left(\mathrm{CaHCO}_{3}{ }^{+}\right.$, $\mathrm{CaCO}_{3}, \mathrm{CaSO}_{4}, \mathrm{MgHCO}_{3}{ }^{+}, \mathrm{MgCO}_{3}, \mathrm{MgOH}^{+}, \mathrm{MgSO}_{4}$ ) consuming $\mathrm{Ca}^{2+}$ and $\mathrm{Mg}^{2+}$ (Fig. 9). These results lead to a slightly increased amount of $\mathrm{Ca}^{2+}$ and a decreased amount of $\mathrm{Mg}^{2+}$ for hot LSWI (Fig. 10). They are also confirmed through the relative concentration of ions. The relative concentration of $\mathrm{Ca}^{2+}$ of hot LSWI shows slightly higher value than that of LSWI (Fig. 7). Consequently, hot LSWI slightly increases the average equivalent fraction of $\mathrm{Ca}^{2+}$ by $9 \%$ and decreases the average equivalent fraction of $\mathrm{Mg}^{2+}$ by $3 \%$ compared to LSWI. The increased equivalent fraction of $\mathrm{Ca}^{2+}$ indicates that the wettability modification effect is enhanced during hot LSWI. The mineral dissolution produces $\mathrm{HCO}_{3}{ }^{-}$as well as cations. The $\mathrm{HCO}_{3}{ }^{-}$also generates $\mathrm{CO}_{2}$ and the $\mathrm{CO}_{2}$ remains as $\mathrm{CO}_{2}$ (aq), not $\mathrm{CO}_{2}$ (gas), due to solubility (Fig. 11). Additionally, hot LSWI reduces the viscosity of heavy oil from $111 \mathrm{cP}$ to $41 \mathrm{cP}$, as indicated in Fig. 1. As a result, hot LSWI introduces synergistic effects of wettability modification and oil viscosity reduction and increases oil recovery up to $56 \%$ (Fig. 6).

\subsection{Pilot-scaled system: hot LSWI}

Next, we evaluated the performance of hot LSWI in a heterogeneous permeable reservoir. The reservoir properties are described in Table 4. The reservoir system has a permeability distribution as depicted in Fig. 12. Another necessary factor to consider in thermal EOR is the heat loss to the over-burden and under-burden shale formations. Table 4 also describes the heat capacity and thermal conductivity of the shale and carbonate formations. The analytical model developed by Vinsome and Westerveld (1980) calculates heat loss from reservoir to over-burden and under-burden formations. Injection of brine is designed with $150 \mathrm{~m}^{3} /$ day and total $1.5 \mathrm{PV}$ is injected. Hot LSWI heated to $115^{\circ} \mathrm{C}$ before injection is deployed into this reservoir and the production from hot LSWI is compared to that of LSWI.

The quarter of five-spot system with one injector and one producer is considered (Fig. 13). When hot LSWI is applied to a pilot-scaled system, the temperature of the reservoir increases up to $114{ }^{\circ} \mathrm{C}$ (Fig. 13a) despite of heat loss to over-burden and under-burden formations. It results in a reduction in oil viscosity down to $59 \mathrm{cP}$ improving the mobility ratio (Fig. 13b). The hot LSWI is compared to SWI and LSWI in terms of geochemical reactions and
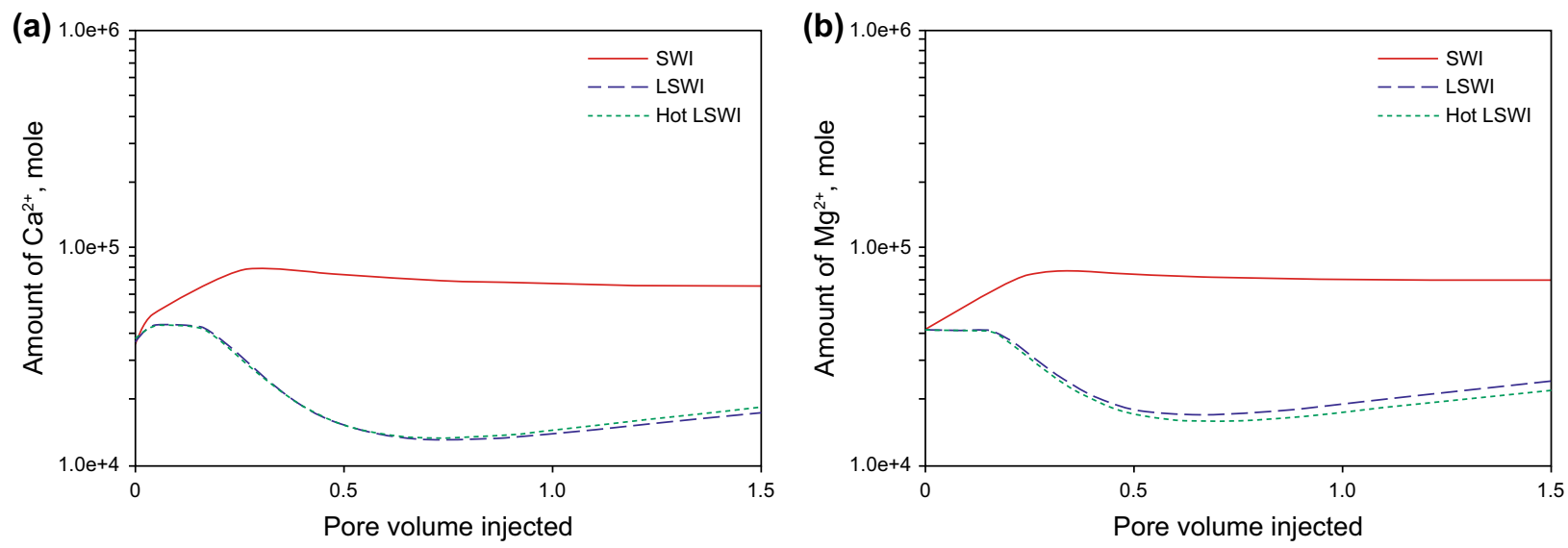

Fig. 15 The amount (mole) of $\mathrm{Ca}^{2+}$ (a) and $\mathrm{Mg}^{2+}$ (b) for SWI, LSWI, hot LSWI 
(a)

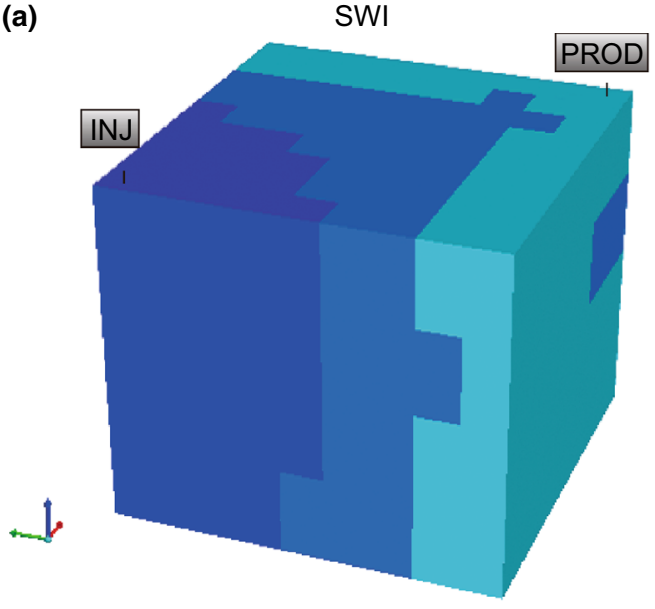

(b)

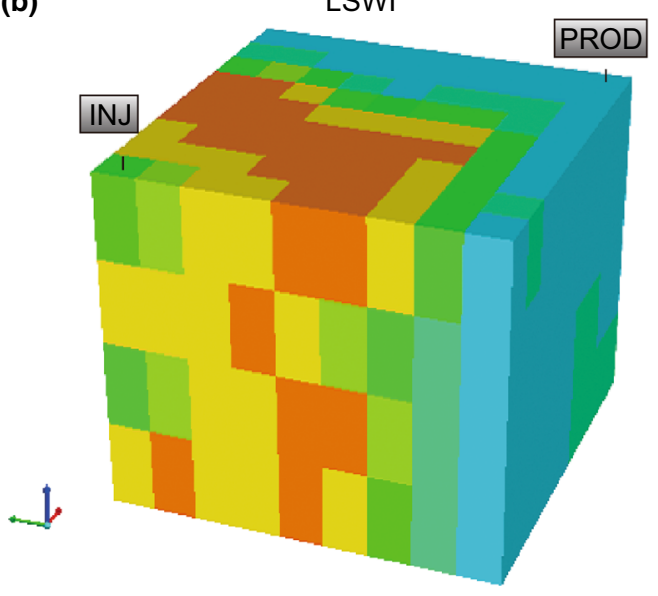

(c)

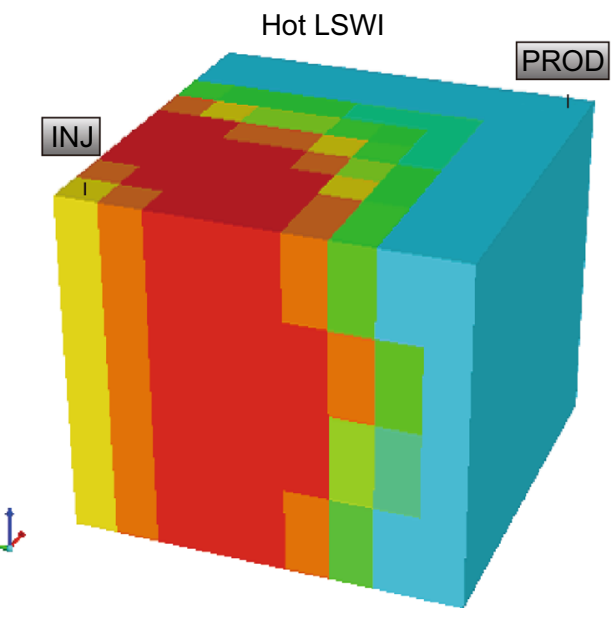

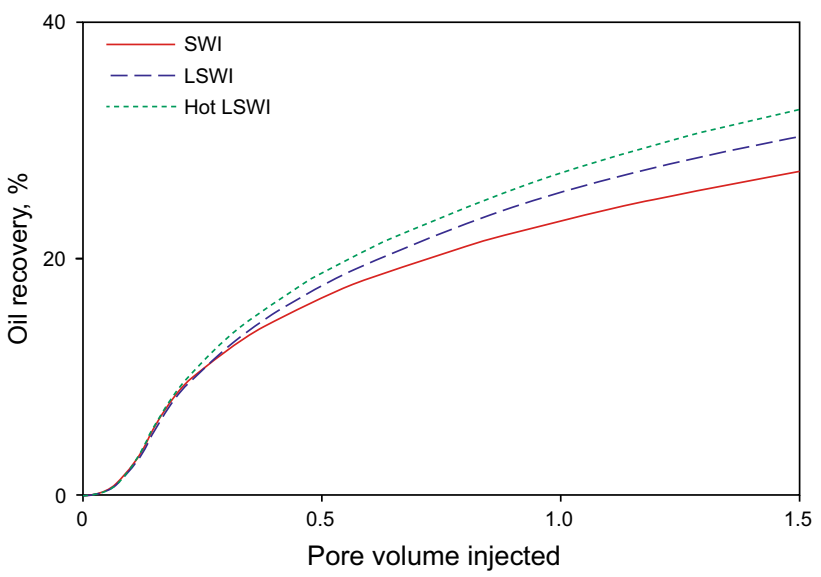

Fig. 17 History of oil recovery (\%) for SWI, LSWI, and hot LSWI

wettability modification effect. Dissolution and precipitation of calcite and dolomite minerals are investigated (Fig. 14). The dissolution/precipitation of minerals change amount of cation in the pilot-scaled reservoir (Fig. 15). In comparison to SWI, LSWI dissolves more calcite minerals by $230 \%$. Hot LSWI dissolves more calcite mineral by $15 \%$ over LSWI because geochemical reaction is sensitive to temperature. In comparison to LSWI, more calcite dissolution during hot LSWI leads to an increased amount of $\mathrm{Ca}^{2+}$ by $5 \%$. In terms of dolomite mineral reaction, both LSWI and hot LSWI result in precipitation. The precipitation of dolomite during hot LSWI is higher than that during LSWI. The higher dolomite precipitation by $88 \%$ decreases the amount of $\mathrm{Mg}^{2+}$ in the reservoir by $8 \%$. For both LSWI and hot LSWI, the dissolution of calcite is much higher than the precipitation of dolomite so that overall mineral dissolution rather than precipitation is dominant.

Next, we evaluated the ion-exchange of $\mathrm{Ca}^{2+}$ contributing to wettability modification during SWI, LSWI, and hot LSWI (Fig. 16). The equivalent fraction of $\mathrm{Ca}^{2+}$ increases up to 0.16 after SWI of 1.5 PV. LSWI and hot LSWI lead to more ion-exchange of $\mathrm{Ca}^{2+}$ increasing the equivalent fractions up to 0.39 and 0.43 , respectively. In comparison to SWI, the equivalent fraction during LSWI increases by $240 \%$. In addition, the hot LSWI has a $10 \%$ higher average equivalent fraction of $\mathrm{Ca}^{2+}$ over LSWI. It means the wettability modification effect is enhanced during hot LSWI compared to LSWI. As a result, LSWI and hot LSWI produce 3\% and 6\% additional oil over SWI, respectively (Fig. 17). The increased oil recovery during hot LSWI is attributed to synergistic effects of oil viscosity reduction and enhanced wettability modification.
Fig. 16 Equivalent fraction of $\mathrm{Ca}^{2+}$ after SWI (a), LSWI (b), and hot LSWI (c) 

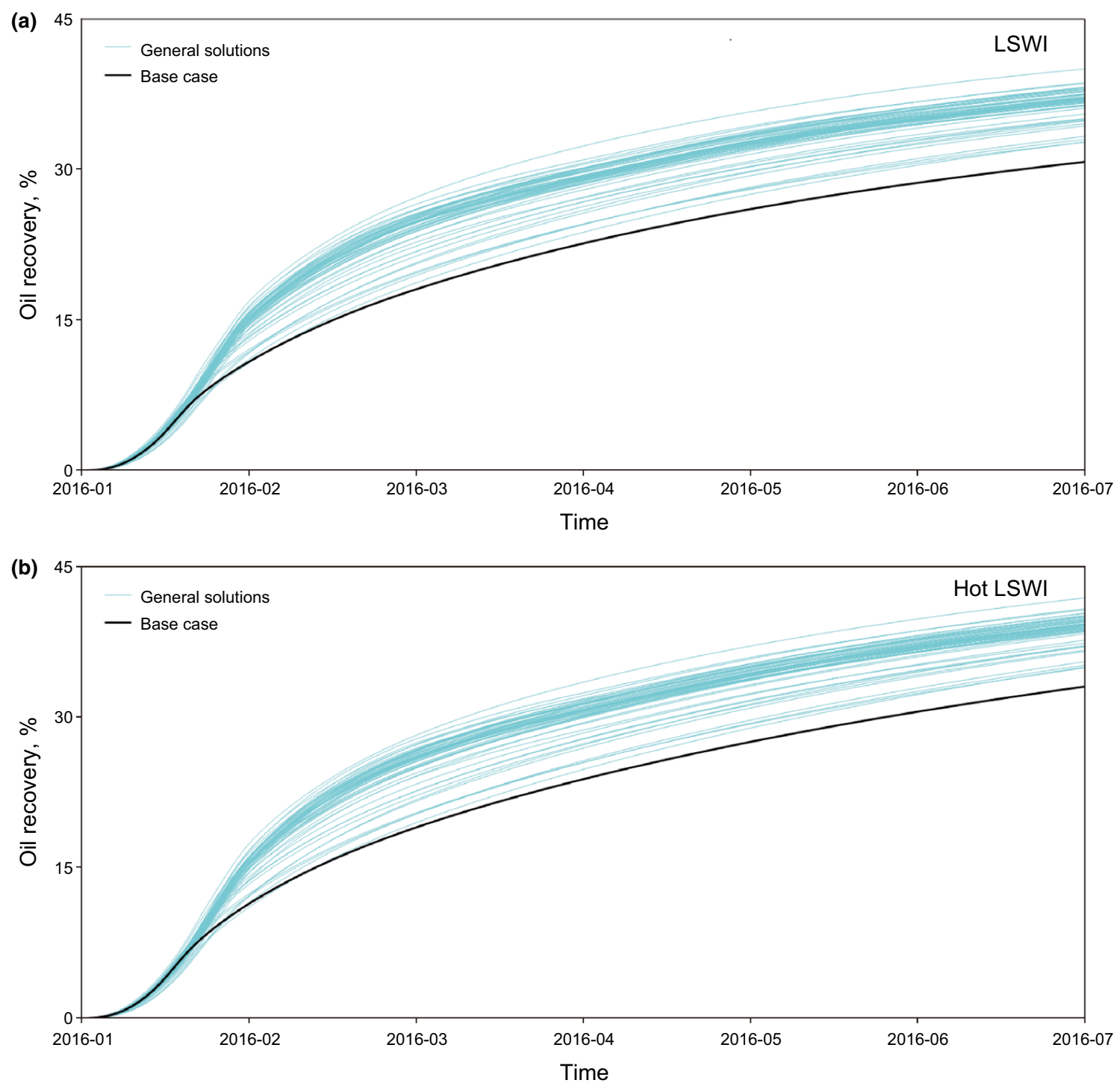

Fig. 18 Oil recovery (\%) of history-matched models for LSWI (a) and hot LSWI (b)

\subsection{Probabilistic forecast of hot LSWI}

To assess inherent uncertainties in the history matching process, a probabilistic forecast method is employed for LSWI and hot LSWI simulations in a pilot-scaled reservoir. Multiple relative permeability curves from 58 historymatched models containing less than $1.5 \%$ matching errors (Fig. 2) are subjected to the assessment of probabilistic forecast. Oil recoveries are calculated from the simulations of LSWI and hot LSWI, respectively (Fig. 18). LSWI produces oil recovery from $30 \%$ to $40 \%$ and hot LSWI produces oil recovery from $33 \%$ to $42 \%$. Uncertainty assessments based on the simulations are carried out using a radial basis function neural network modeling and Monte-Carlo simulation. The assessment has estimated
P90, P50, and P10 in cumulative distribution function of oil recovery. The P90, P50, and P10 are defined as the oil recovery corresponding to percentile of 90,50 , and 10 , respectively. Figure 19 denotes the results of Monte-Carlo simulation for LSWI and hot LSWI. In LSWI, the P10, P50, and P90 of oil recovery are about 29\%, 32\%, and $38 \%$, respectively. Estimated P10 and P90 of oil recovery indicate conservative and optimistic oil recoveries. There is approximately $11 \%$ of difference between P90 and P10. For hot LSWI, P10, P50, and P90 of oil recovery are 32\%, $35 \%$, and $40 \%$, respectively. The optimistic oil recovery has $8 \%$ higher than conservative oil recovery in hot LSWI. Despite the uncertainty to predict oil production, hot LSWI enhances heavy oil production by synergistic effects. 

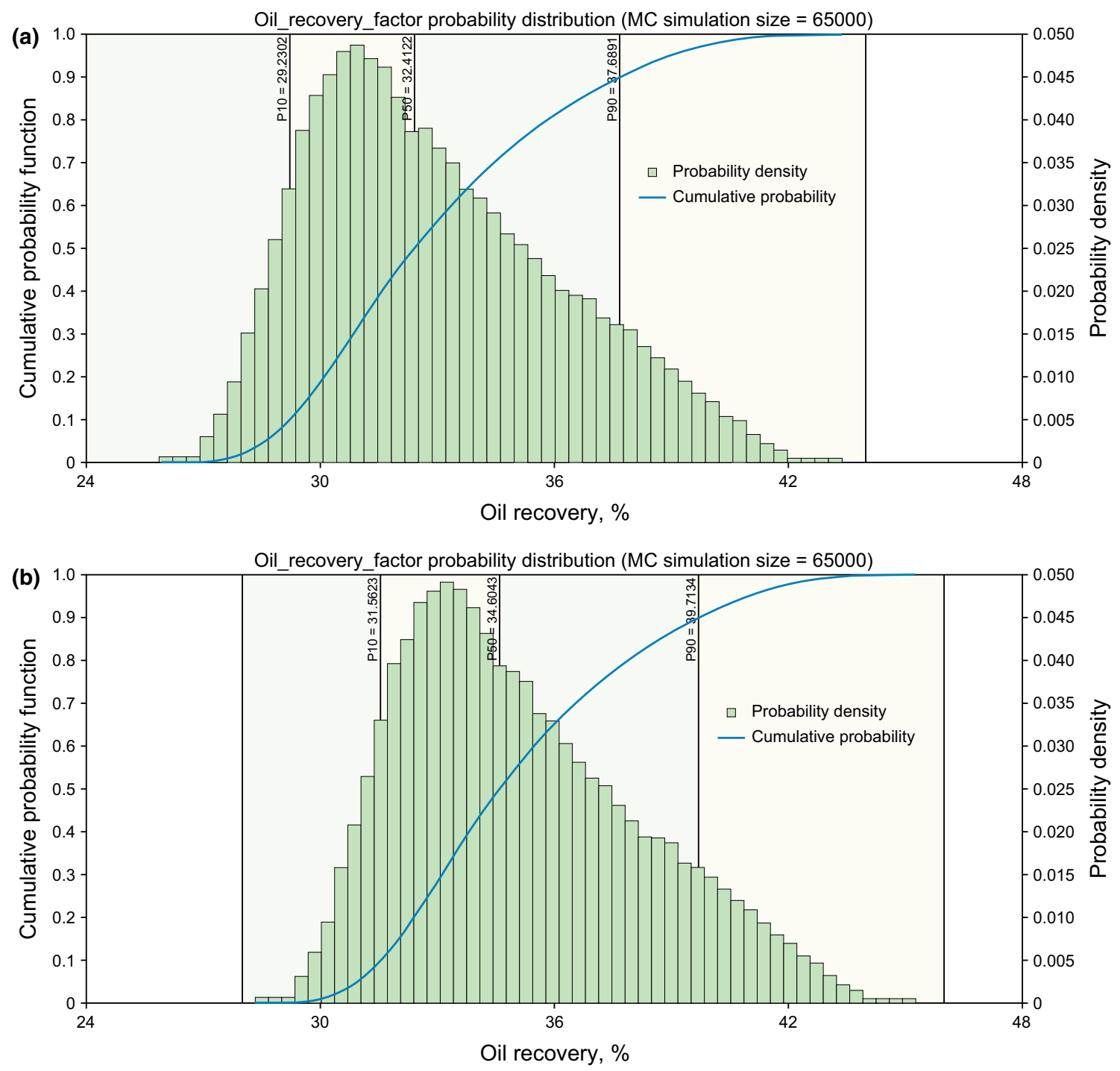

Fig. 19 Monte-Carlo simulations of LSWI and hot LSWI in terms of oil recovery (\%)

\section{Conclusions}

This study models hot LSWI process and evaluates synergistic effects of hot LSWI to enhance heavy oil production. The synergistic effects of oil viscosity reduction and wettability modification are evaluated during hot LSWI. The wettability modification is investigated in terms of geochemical reactions. This study tests the viability of the hot LSWI in core- and pilot-scaled systems. The following conclusions are drawn from this study.

In comparison to LSWI, the thermal energy of hot LSWI influences geochemical reactions and oil viscosity. In a core-scaled system, both LSWI and hot LSWI lead to ionexchange of $\mathrm{Ca}^{2+}$ and $\mathrm{Mg}^{2+}$ modifying wettability. In comparison to SWI, LSWI and hot LSWI increase the equivalent fraction of $\mathrm{Ca}^{2+}$ by $182 \%$ and $209 \%$ as a result of ion-exchange. In comparison to LSWI, the hot LSWI dissolves more mineral and produces $\mathrm{Ca}^{2+}$ in the system. The mineral dissolution slightly increases the equivalent fraction enhancing wettability modification for hot LSWI. In an assessment of the pilot-scaled system, LSWI and hot LSWI provide $240 \%$ and $268 \%$ higher equivalent fraction over SWI and improve wettability. In comparison to LSWI, hot LSWI produces higher equivalent fraction by $10 \%$ because of more calcite dissolution. This result also implies the enhanced wettability modification effect during hot LSWI. Another key factor to determine oil recovery is the oil viscosity. While LSWI has favorable wetness to recover oil, the oil recovery increase is 3\%. Hot LSWI reduces oil viscosity by $63 \%$. Therefore, $3 \%$ more movable oil can be recovered in the hot LSWI process. Finally, a probabilistic forecast with uncertainty assessment evaluates the feasibility of hot LSWI by comparing LSWI. It confirms that hot LSWI enables the production of additional heavy oil 
due to enhanced wettability modification and oil viscosity reduction effects.

Acknowledgements This work was financially supported by the Energy Efficiency and Resources of the Korea Institute of Energy Technology Evaluation and Planning (KETEP) Grant funded by the Korea government Ministry of Knowledge Economy (No. 20172510102290).

Open Access This article is distributed under the terms of the Creative Commons Attribution 4.0 International License (http://creative commons.org/licenses/by/4.0/), which permits unrestricted use, distribution, and reproduction in any medium, provided you give appropriate credit to the original author(s) and the source, provide a link to the Creative Commons license, and indicate if changes were made.

\section{References}

Abass E, Fahmi A. Experimental investigation of low salinity hot water injection to enhance the recovery of heavy oil reservoirs. In: North Africa technical conference and exhibition, 15-17 April, Cairo, Egypt; 2013. http://dx.doi.org/10.2118/164768-MS.

Alajmi AFF, Algharaib MK, Gharbi RC. 2009. Experimental evaluation of heavy oil recovery by hot water injection in a Middle Eastern reservoir. In: SPE middle east oil and gas show and conference, 15-18 March, Manama, Bahrain; 2009. http:// dx.doi.org/10.2118/120089-MS.

Appelo CAJ, Postma D. Geochemistry, groundwater and pollution. 2nd ed. Leiden: Balkema AA; 2005.

Austad T, Strand S, Høgnesen EJ, Zhang P. Seawater as IOR fluid in fractured chalk. In: SPE international symposium on oilfield chemistry, 2-4 February, The Woodlands, Texas; 2005. http:// dx.doi.org/10.2118/93000-MS.

Awolayo AN, Sarma HK, Nghiem LX. A Comprehensive geochemical-based approach at modeling and interpreting brine dilution in carbonate reservoirs. In: SPE reservoir simulation conference, 20-22 February, Montgomery, Texas; 2017. http://dx.doi.org/10. 2118/182626-MS.

Ayirala S, Al-Saleh SH, Enezi S, Yousef A. Effect of salinity and water ions on electrokinetic interactions in carbonate reservoir cores at elevated temperatures. SPE Res Eval Eng. 2018;21(3):733-46. https://doi.org/10.2118/189444-PA.

Bethke CM. Geochemical and biogeochemical reaction modeling. 2nd ed. New York: Cambridge University Press; 2007.

Delany JM, Lundeen SR. The LLNL thermochemical data baserevised data and file format for the EQ3/6 package: UCID21658. Livermore: Lawrence Livermore National Laboratory; 1991.

Duval K, Gutiérrez D, Petrakos D, Ollier P, Johannson D. Successful application of hot-water circulation in the Pelican Lake field: results and analyses of the E29 hot-water-injection pilot. J Can Pet Technol. 2015;54(6):361-71. https://doi.org/10.2118/ 174491-PA.

Gachuz-Muro H, Sohrabi M. Effects of brine on crude oil viscosity at different temperature and brine composition-heavy oil/water interaction. In: EAGE annual conference \& exhibition incorporating SPE Europec, 10-13 June, London, UK; 2013. http://dx. doi.org/10.2118/164910-MS.

Gachuz-Muro H, Sohrabi M. Smart water injection for heavy oil recovery from naturally fractured reservoirs. In: SPE heavy and extra heavy oil conference, 24-26 Sept, Latin America; 2014. http://dx.doi.org/10.2118/171120-MS.
Guo K, Li H, Yu Z. In-situ heavy and extra-heavy oil recovery: a review. Fuel. 2016;185:886-902. https://doi.org/10.1016/j.fuel. 2016.08.047.

Hiorth A, Cathles LM, Madland MV. The impact of pore water chemistry on carbonate surface charge and oil wettability. Transp Porous Media. 2010;85(1):1-21. https://doi.org/10.1007/ s11242-010-9543-6.

Kharaka YK, Gunter WD, Aggarwal PK, Perkins EH, DeBraal JD. SOLMINEQ.88, A computer program for geochemical modeling of water-rock interactions. water resources investigation report 88-4227, US Geological Survey, Menlo Park, California, 1988.

Kestin J, Khalifa HE, Correia RJ. Tables of the dynamic and kinematic viscosity of aqueous $\mathrm{NaCl}$ solutions in the temperature range $20-150^{\circ} \mathrm{C}$ and the pressure range $0.1-35 \mathrm{MPa}$. J Phys Chem Ref Data. 1981;10(1):71. https://doi.org/10.1063/1. 555641.

Kovscek AR, Diabira I, Castanier LM. An experimental investigation of permeability and porosity alteration in diatomite during hot fluid injection. In: SPE/AAPG western regional meeting, Long Beach, California, 19-22 June, 2000. http://dx.doi.org/10.2118/ 62558-MS.

Lager A, Webb KJ, Black CJJ, Singleton M, Sorbie KS. Low salinity oil recovery-an experimental investigation 1. Petrophys. 2008;49(1):28-35.

Lake LW, Johns RT, Rossen WR, Pope GA. Fundamentals of enhanced oil recovery. Texas: Society of Petroleum Engineers; 2014.

Lapham N. Enhanced oil recovery. 2nd ed. Rockvill, Maryland: SBI Energy; 2012.

Meyer RF, Attanasi ED, Freeman PA. Heavy oil and natural bitumen: Strategic petroleum resources. United States Geological Survey. 2003.

Morse JW, Arvidson RS. The dissolution kinetics of major sedimentary carbonate minerals. Earth Sci Rev. 2002;58(1-2):51-84. https://doi.org/10.1016/S0012-8252(01)00083-6.

Nghiem L, Sammon P, Grabenstetter J, Ohkuma H. Modeling $\mathrm{CO}_{2}$ storage in aquifers with a fully-coupled geochemical EOS compositional simulator. In: SPE/DOE symposium on improved oil recovery, 17-21 April, Tulsa, Oklahoma; 2004. https://doi. org/10.2118/89474-MS.

Pedersen KS, Fredenslund A. An improved corresponding states model for the prediction of oil and gas viscosities and thermal conductivities. Chem Eng Sci. 1987;42(1):182-6. https://doi.org/ 10.1016/0009-2509(87)80225-7.

Qiao C, Johns R, Li L, Xu J. Modeling low salinity waterflooding in mineralogically different carbonates. In: SPE annual technical conference and exhibition, 28-30 September, Houston, Texas; 2015. http://dx.doi.org/10.2118/175018-MS.

Rowe AM, Chou JCS. Pressure-volume-temperature-concentration relation of aqueous sodium chloride solutions. J Chem Eng Data. 1970;15(1):61-6. https://doi.org/10.1021/je60044a016.

Saidi AM. Reservoir engineering of fractured reservoirs: fundamental and practical aspects. Total ed. Paris: Press; 1988.

SenGupta AK. Ion exchange in environmental processes: fundamentals, application and sustainable technology. Hoboken: Wiley; 2017.

Soulaine C, Roman S, Kovscek A, Tchelepi HA. Mineral dissolution and wormholing from a pore-scale perspective. J Fluid Mech. 2017;827:457-83. https://doi.org/10.1017/jfm.2017.499.

Vinsome PKW, Westerveld J. A simple method for predicting cap and base rock heat losses in thermal reservoir simulators. J Can Pet Technol. 1980;9(3):87-90. https://doi.org/10.2118/80-03-04.

Wolery TJ. EQ3NR, a computer program for geochemical aqueous speciation-solubility calculations: theoretical manual, user's guide, and related documentation (Version 7.0). Laboratory Report No. UCRL-MA-110662 (3), Livermore, Lawrence 
Livermore Laboratory, University of California, California. 1992.

Wolthers M, Charlet L, Cappellen PV. The surface chemistry of divalent metal carbonate minerals; a critical assessment of surface charge and potential data using the charge distribution multi-site ion complexation model. Am J Sci. 2008;308(8):905-41. https://doi.org/10.2475/08.2008.02.

Yousef AA, Al-Saleh SH, Al-Kaabi A, Al-Jawfi MS. Laboratory investigation of the impact of injection-water salinity and ionic content on oil recovery from carbonate reservoirs. SPE Res Eval Eng. 2011;14(5):578-93. https://doi.org/10.2118/137634-PA.

Yutkin MP, Mishra H, Patzek TW, Lee J, Radke CJ. Bulk and surface aqueous speciation of calcite: implications for low-salinity waterflooding of carbonate reservoirs. SPE J. 2018;3(01):84-101. https://doi.org/10.2118/182829-PA.

Zhang P, Tweheyo MT, Austad T. Wettability alteration and improved oil recovery in chalk: the effect of calcium in the presence of sulfate. Energy Fuels. 2006;20(5):2056-62. https:// doi.org/10.1021/ef0600816.

Zhang P, Tweheyo MT, Austad T. Wettability alteration and improved oil recovery by spontaneous imbibition of seawater into chalk: impact of the potential determining ions: $\mathrm{Ca}^{2+}$, $\mathrm{Mg}^{2+}$, and $\mathrm{SO}_{4}{ }^{2-}$. Colloids Surf A Physicochem Eng Asp. 2007;301(1-3):199-208. https://doi.org/10.1016/j.colsurfa.2006. 12.058. 